\title{
The Regime Shifts Database: a framework for analyzing regime shifts in social-ecological systems
}

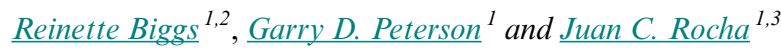

\begin{abstract}
Regime shifts, i.e., large, persistent, and usually unexpected changes in ecosystems and social-ecological systems, can have major impacts on ecosystem services, and consequently, on human well-being. However, the vulnerability of different regions to various regime shifts is largely unknown because evidence for the existence of regime shifts in different ecosystems and parts of the world is scattered and highly uneven. Furthermore, research tends to focus on individual regime shifts rather than comparisons across regime shifts, limiting the potential for identifying common drivers that could reduce the risk of multiple regime shifts simultaneously. Here, we introduce the Regime Shifts Database, an open-access database that systematically synthesizes information on social-ecological regime shifts across a wide range of systems using a consistent, comparative framework, providing a wide-ranging information resource for environmental planning, assessment, research, and teaching initiatives. The database currently contains 28 generic types of regime shifts and $>300$ specific case studies. Each entry provides a literature-based synthesis of the key drivers and feedbacks underlying the regime shift, as well as impacts on ecosystem services and human well-being, and possible management options. Across the 28 regime shifts, climate change and agriculture-related activities are the most prominent among a wide range of drivers. Biodiversity, fisheries, and aquatic ecosystems are particularly widely affected, as are key aspects of human well-being, including livelihoods, food and nutrition, and an array of cultural ecosystem services. We hope that the database will stimulate further research and teaching on regime shifts that can inform policy and practice and ultimately enhance our collective ability to manage and govern large, abrupt, systemic changes in the Anthropocene.
\end{abstract}

Key Words: alternative stable state; critical transition; ecosystem service; human well-being; phase transition; regime shift; social-ecological system; threshold; tipping point

\section{INTRODUCTION}

Much of the time, changes in ecosystems and social-ecological systems (SESs) are experienced as relatively slow and incremental, but from time-to-time dramatically large, persistent, and often unexpected changes take place. Such large, persistent changes are commonly referred to as regime shifts (Scheffer et al. 2001, Biggs et al. 2012). These shifts can have major impacts on human economies, security, and health because they affect the supply of essential ecosystem services on which human societies depend, such as crop production, flood regulation, and cultural identity (Millennium Ecosystem Assessment 2005, Crépin et al. 2012). Obtaining a better understanding of the potential risks and consequences of regime shifts has been identified as a priority in global environmental change research (Carpenter et al. 2009, Reid et al. 2010), particularly in the context of global research and assessment processes such as Future Earth (http://www. futureearth.org/), the Intergovernmental Panel on Climate Change (http://www.ipcc.ch/), and the Intergovernmental Platform on Biodiversity and Ecosystem Services (IPBES, http:// www.ipbes.net/).

Regime shifts arise because ecosystems and SESs are complex adaptive systems that can shift from being organized around one set of dominant, reinforcing processes and structures to another (Scheffer 2009, Levin et al. 2013; Box 1). At a theoretical level, such systemic reorganization of systems correspond to critical transitions between different mathematical attractors or alternative stable states, separated by critical thresholds or tipping points (Scheffer 2009, Lenton 2013). While these shifts can be sudden and dramatic, the large, persistent changes that characterize regime shifts can also unfold slowly and almost imperceptibly, especially at regional and global scales (Hughes et al. 2013b). Empirically, regime shifts have been documented across a range of systems and include phenomena such as the collapse of important fisheries (Carpenter 2003), the salinization of agricultural soil (Anderies et al. 2006), and shifts between savanna and forest biomes (Staver et al. 2011). Regime shifts have been mostly documented at local and regional scales (e.g., Gordon et al. 2008, Lenton et al. 2008, Mård Karlsson et al. 2011, Nyström et al. 2012), but can also occur at global scales or potentially propagate across scales to trigger global-scale regime shifts (Barnosky et al. 2012, Hughes et al. 2013a).

Box 1: Understanding regime shifts: a systems dynamics perspective

One of the key ways of analyzing and understanding systems is to identify the key feedback loops that regulate system dynamics (Meadows 2008). Systems can be viewed as networks of elements linked by feedback loops, which can be either balancing (counteracting change) or reinforcing (enhancing change). In some systems, the same set of feedbacks always dominates so that the system always has a similar structure (e.g., dominated by grasses) and functions in broadly the same way. However, in many complex systems, more than one configuration of dominant feedbacks (in terms of structuring the flow of matter and energy in the system) is possible. Which configuration is dominant at a

\footnotetext{
${ }^{1}$ Stockholm Resilience Centre, Stockholm University, Sweden, ${ }^{2}$ Centre for Complex Systems in Transition, Stellenbosch University, South Africa,
}

${ }^{3}$ Beijer Institute of Ecological Economics, Swedish Royal Academy of Sciences, Sweden 
particular point in time depends on the starting conditions of the system and its history of disturbances and pressures (Scheffer 2009).

If more than one configuration is possible, a specific set of feedback loops will tend to become dominant over time so that the system becomes structured and functions in a particular way, forming a particular regime (Biggs et al. 2012; Fig. 1). This process occurs because at least some of the dominant feedbacks are usually reinforcing, creating conditions that enhance the persistence of the particular regime, making it "sticky" once it forms. Importantly, a regime does not refer to a single condition of a system, but to a range of conditions across which the system may fluctuate while retaining a similar structure and function. Regimes, basins of attraction, or alternative stable states are all concepts that denote this range of conditions.

A regime shift occurs when a switch in the dominant feedbacks occurs and is often associated with rapid nonlinear change as the system reorganizes into a different structure and starts functioning in a different way. Such a switch can occur when a large shock (e.g., hurricane) overwhelms the dominant system feedbacks or changes the direction of a reinforcing feedback. More commonly, a gradual change (e.g., habitat loss) slowly erodes the strength of the dominant feedbacks until a critical threshold or tipping point is reached at which a different set or direction of feedbacks becomes dominant, and the system reorganizes into a new regime (Fig. 1). Drivers of regime shifts (both shocks and gradual changes) are usually external variables that directly or indirectly influence the feedback dynamics of the system.

The slow erosion of feedbacks and associated loss of resilience usually goes unnoticed until the actual regime shift occurs; hence, the shift often comes as a surprise. Furthermore, because one or more reinforcing feedbacks will usually underlie the new regime, regime shifts are often costly or impossible to reverse (Scheffer et al. 2001). In other cases, it may be possible to reverse regime shifts or facilitate shifts to new, more desirable regimes through interventions that affect key feedbacks, variables, or drivers. Such points of systemic intervention are known as leverage points and are key to manipulating system dynamics (Meadows 2008).

Despite the accumulating empirical base, evidence for the existence of regime shifts in different ecosystems and different parts of the world is scattered and highly uneven (Rocha et al. $2015 b$ ). In most parts of the world, the regime shifts to which a particular region may be vulnerable under different land uses or under conditions such as a changing climate are largely unknown, as are the effects of potential regime shifts on ecosystems, ecosystem services, and human well-being. Such information is critical to sustainable development planning and to assessments of social and ecological resilience, which are increasingly central to development policy (Resilience Alliance 2007, Reyers et al. 2018). Furthermore, most research tends to focus on individual regime shifts rather than comparisons across regime shifts. Comparative analysis of drivers and impacts of regime shifts occurring in different system types and world regions could help to identify the priority regime shifts and regions for policy action, as well as leverage points that could reduce the risk of multiple regime shifts simultaneously and help avoid cascading sets of interlinked regime shifts.
Fig. 1. A stylized representation of a shift from Regime 1 to Regime 2, and the associated shift in dominant feedback loops linking variables A, B, and C. In Regime 1, Feedbacks 1 (balancing) and 2 (reinforcing) are dominant in terms of structuring the flow of material and energy in the system; in Regime 2, Feedbacks 2 (reinforcing in the opposite direction) and 3 (balancing) are dominant. A shift from Regime 1 (dominated by variable B) to Regime 2 (dominated by variable C) can be triggered by either a large shock or gradual internal or external change that erodes of the strength of the dominant balancing feedbacks or changes the direction of the reinforcing feedback regulated by variable $\mathrm{A}$.

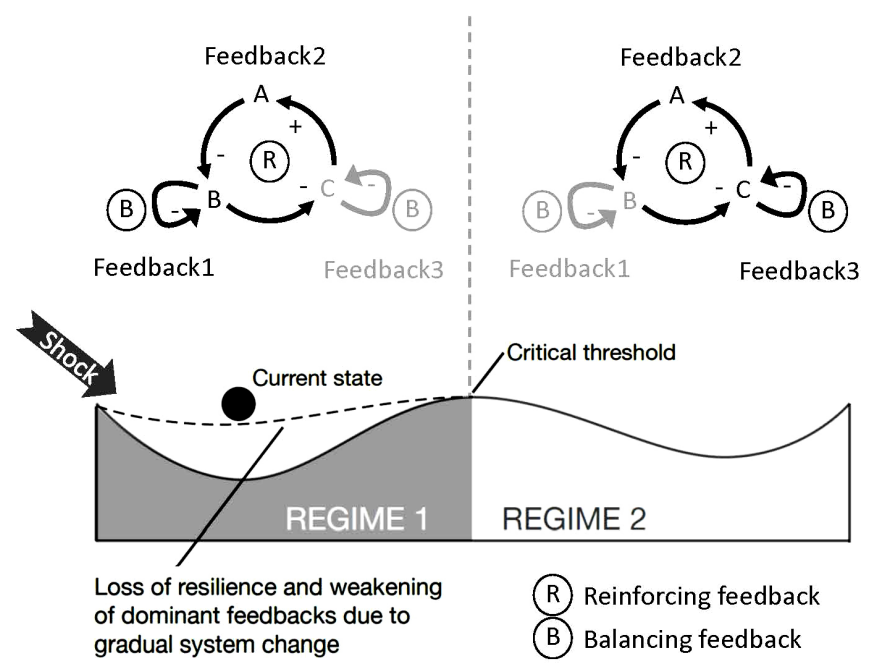

The current lack of comparative synthesis across regime shifts is partly due to a lack of agreement on practical, operational criteria for identifying and analyzing regime shifts across different system types and disciplines (Lees et al. 2006, Andersen et al. 2009). In fields such as oceanography, large, statistically significant step changes in ecosystems are typically regarded as regime shifts (Conversi et al. 2014). In contrast, in ecosystem ecology and earth system science, much more emphasis is placed on whether feedback processes have reorganized in a way that moves the system toward a different attractor (Scheffer et al. 2001, Lenton 2013). These definitions do not always align because large, abrupt changes in a system can arise from a sudden change in a driver or from a nonlinear relationship between a key driver and response variable and not necessarily from a systemic reorganization of feedback processes within the system (Andersen et al. 2009). Furthermore, in many empirical cases in which there is a limited understanding of system processes and the data are noisy, it may be very difficult to identify the mechanisms underlying a particular large, abrupt change. It often takes decades to establish whether processes underlying an observed step change are capable of generating alternative attractors (e.g., Schindler 2006). In addition, internal and external system dynamics can cause attractors to vary over time scales comparable to the dynamics of the system, further hampering the identification of different attractors (Biggs et al. 2009).

Here, we introduce the Regime Shifts Database (RSDB, http:// www.regimeshifts.org/), a novel platform for cross-system 
comparative synthesis of regime shifts and their consequences for human well-being. The aim of the RSDB is to support environmental research, teaching, and assessment initiatives at national, regional, and global scales. The RSDB is based on a comparative framework that we developed to synthesize policyrelevant information on regime shifts systematically and consistently across a diverse range of social-ecological, terrestrial, and marine systems. The RSDB adopts a pragmatic, anthropocentric approach to deal with the issues of inconsistent definitions and criteria for identifying regime shifts. We argue that from the point of view of the people living in an SES, it is useful to know that a system can potentially experience large, abrupt, persistent systemic changes even if the underlying mechanisms are not yet fully understood. The database therefore focuses on identifying large systemic changes that are policy relevant, in that they affect ecosystem services, and where there are established or at least proposed changes in feedbacks that make the systemic changes difficult to reverse. Our goal is to translate regime shift ideas into a pragmatic framework that can usefully inform policy and planning in the face of incomplete information in a rapidly changing world.

We first introduce the database and criteria we use for selecting examples for inclusion. We then describe the framework we developed for analyzing examples of regime shifts across different system types and reflect on our learnings to date. Finally, we present a synthesis of the examples included in the RSDB to date, highlighting emerging patterns and possible avenues for further research.

\section{THE REGIME SHIFTS DATABASE}

The Regime Shifts Database (RSDB) systematically compiles examples of regime shifts in ecosystems and SESs that have consequences for ecosystem services and human well-being and aims to provide an entry point to policy-relevant regime shifts for purposes of research, teaching, and environmental management. The database is freely available online at http://www.regimeshifts. org, and each entry includes an explanation of the underlying drivers and dynamics that lead to the shift, as well as the impacts on ecosystem services and human well-being. The database can be searched, for instance, for regime shifts influenced by a particular driver, occurring in a particular ecosystem or land-use type, or that have specific ecosystem service or human well-being impacts. In addition, a variety of open-source materials such as images and simple models are available for teaching purposes.

The examples included in the RSDB are based on the literature and also draw on examples from the Thresholds Database (Walker and Meyers 2004). The three key criteria for inclusion of examples in the RSDB are: (1) a large change or reorganization of an SES has been observed or proposed; (2) the change affects the set of ecosystem services provided by the SES, with potential consequences for human well-being; and (3) established or proposed feedback mechanisms exist that create and maintain the different regimes so that the change is persistent and not readily reversible.

Entries in the database include well-established regime shifts as well as contested and speculative regime shifts. It often takes many years to conclusively establish that a particular change is in fact a regime shift involving systemic reorganization of feedback processes. However, it may be crucial from a management perspective to know that a regime shift may exist, even if the evidence is still speculative or contested. There are also a substantial number of cases in the literature in which regime shiftlike phenomena have been observed and described but have not necessarily been referred to as regime shifts. The RSDB aims to capture all of these examples if they potentially affect ecosystem services and human well-being. For each example, the level of certainty regarding the existence of a regime shift, as well as the level of certainty about the underlying dynamics that cause the shift, are recorded based on an assessment of the information and level of agreement in the literature.

The database contains three "levels" of regime shifts. The first level focuses on different "generic types" of regime shifts such as lake eutrophication or shrub encroachment. These are general syntheses of regime shifts that have been observed in many localities around the world. The second and third levels are, respectively, detailed and basic case studies of particular regime shifts in specific places. The detailed case studies provide detailed information and analysis of a specific regime shift, for example, eutrophication in the Baltic Sea. The basic case studies provide only a brief description of a specific case and key references and are usually linked to a generic description of a particular regime shift.

The database has been structured in a hierarchical way so that information can be entered in the form of (1) a short summary (basic case studies only), (2) a more extensive narrative description summarizing the regime shift dynamics and effects (detailed case studies and generic regime shifts), and (3) a detailed regime shift analysis. The different options enable users to contribute to the database at different levels of detail. The short summary enables additional case studies of regime shifts already described in the database to be added easily, as the underlying dynamics are already captured in the generic description. In most cases, the more extensive narrative description is based on a detailed regime shift analysis, although some users choose only to complete the narrative description.

To ensure data quality, each generic regime shift or detailed case study is reviewed by a regime shift researcher or domain expert prior to publication on the Internet. We have also included a webbased form for comments so that users can provide feedback and updates on the regime shift descriptions and be engaged in improving the database. To facilitate use of the information in the database and to acknowledge the effort put into the regime shift descriptions, each published entry has a citable reference.

\section{Regime shift analysis framework}

To capture different regime shifts in a consistent way, we developed a systems-based framework for synthesizing the information in the literature. The framework draws on a variety of concepts from systems theory, including soft systems (Checkland and Poulter 2006), causal loop diagrams (Sterman 2000), critical transitions (Scheffer 2009), and resilience theory (Bennett et al. 2005, Biggs et al. 2015). The framework includes three core elements: a causal loop diagram (CLD), a detailed narrative description, and a set of categorical variables that summarizes the regime shift.

The regime shift analysis framework is centered on the construction of a CLD for each regime shift (generic type or 
detailed case study). The CLD summarizes the key drivers and internal feedbacks underlying each regime shift (Meadows 2008) and serves as a visual check on the narrative description (see Box 2). The level of detail depicted in a CLD always requires choice and judgment and depends on the purpose of the diagram (Lane 2008). To enhance consistency across regime shifts, we developed a consistent set of variable names to be used in the CLDs (Appendix 1). We also developed rules for the feedbacks and mechanisms to be included to capture the minimum set of variables, key drivers, and feedbacks that generate the regime shift dynamics. In the case of generic regime shifts such as eutrophication, there may be several different combinations of drivers and feedbacks that can generate a particular regime shift. In these cases, the CLD summarizes all proposed and established mechanisms leading to the shift.

\section{Box 2: Summary of the seagrass transitions regime shift}

Regime shifts in seagrass beds are characterized by the collapse of seagrass beds and a transition to either an algae-dominated regime or a barren sediment regime. Seagrass ecosystems provide valuable ecosystem services such as fishing grounds and coastal protection, which are lost when the shift occurs. Thus, human well-being is affected through impacts on food and nutrition, livelihoods and economic activity, security of housing and infrastructure, as well as aesthetic and recreational values. The regime shift is well established and understood, with evidence in the form of models, contemporary observations, and experiments.

The key direct drivers are nutrient loading from agricultural runoff and overfishing, which both cause slow changes in the system that eventually lead to a sudden collapse of the seagrass regime. Abrupt shocks, including storms, disease outbreaks, and physical removal of seagrass beds associated with coastal development can also trigger or contribute to the regime shift. The main indirect drivers include coastal development and deforestation, greenhouse gas emissions, climate change, ocean acidification, and sea level rise. The regime shift typically occurs at the local scale (e.g., catchment or community) over a time span of months to years.

Fig. 2 depicts the key feedbacks underlying the regime shift dynamics. The seagrass-turbidity reinforcing feedback reflects how seagrass cover reduces turbidity and light penetration, which facilitates further increases in seagrass abundance. Competition between seagrass and algae for nutrients and space is a reinforcing feedback that reinforces the dominant species. The herbivory feedback depicts the balancing effect of herbivores on algae that in turn reinforces the growth of seagrass by reducing competition. The habitat feedback depicts a balancing feedback that denotes density dependence of the population. Although specific thresholds were not identified in the literature, they are thought to be related to the levels of nutrients in the water, light penetration, seagrass density, and herbivory.

Accordingly, leverage points for management include limiting nutrients and other pollutants in coastal areas; adaptive management of fisheries, paying particular attention to the herbivorous populations; and limiting potential physical disturbance associated with development in coastal areas. On a larger scale, dealing with climate change is imperative, although managers at the local level usually do not have the power to influence the physical dynamics of climate or the social dynamics underlying greenhouse gas emissions. Other managerial options include transplantation of seagrass and development of marine conservation areas.

Source: http://www.regimeshifts.org/item/487-seagrass-transitions\#

Accompanying the CLD is a detailed narrative description that covers the following aspects.

- Definition of the system: A brief introduction to the example, clearly defining the SES and its boundaries (e.g., lake and its watershed, including the people living in the landscape). The spatial and temporal boundaries of an SES are typically "open" and can be defined in different ways, depending on the particular focus of the example.

- Alternate regimes: Identification and brief description of the different regimes, focusing on what would be seen in the field (e.g., clear water, rooted plants on the lake floor, limited agriculture in the catchment). Identifying the different regimes is typically the most difficult step in conceptualizing and analyzing each example and usually draws on a combination of observational, experimental, and modeling evidence. For the purposes of informing ecosystem assessments or management, it is usually sufficient to identify the two or three major alternate regimes, although some of these may comprise several subregimes.

- Feedbacks that maintain each regime: A description of the key known or proposed feedback processes that maintain each regime, making it persistent and difficult to reverse. Different regimes are differentiated by substantive differences in the relative strength of existing feedbacks or the appearance of completely new feedbacks (Bennett et al. 2005). For each feedback, the RSDB captures the scale at which the feedback operates (local, regional, or global) as well as the level of uncertainty about the feedback (well established, contested, or speculative).

- Drivers of the regime shift: A description of the key drivers that cause the system to shift between regimes. These include shocks (e.g., droughts, floods), direct and indirect external drivers, and slow internal system changes. A direct driver directly influences the internal feedback processes underlying a regime shift (but is not itself influenced by the feedback), whereas an indirect driver alters one or more direct drivers (Nelson et al. 2006). Because drivers depend on the definition of system boundaries, a driver that is direct in one example may be indirect in another. For each driver, the RSDB captures the scale at which it operates (local, regional, or global) as well as the level of uncertainty about the driver (well established, contested, or speculative). If the shift can happen in two or more directions, the drivers of each shift are described.

- Key thresholds: The approximate levels of key drivers at which a regime shift is triggered, if available in the literature. 
Fig. 2. Causal loop diagram (CLD) for the seagrass transitions regime shift. A CLD consists of variables connected by arrows denoting causal influence, with each relationship being positive (an increase in variable A leads to an increase in variable B or vice versa) or negative (an increase in variable A leads to a decrease in Variable B or vice versa). Closed loops denote feedbacks, which can be either reinforcing (positive) or balancing (negative). Variables that affect the feedback loops but are not themselves affected by or are part of these loops are defined as external drivers (Lane 2008). In the CLD depicted here, colours denote different feedbacks underlying seagrass transitions, and the relationships to external drivers are mapped in black. Dashed lines represent causal connections that are uncertain at the scale at which the regime shift dynamics are described. Red = seagrass-turbidity reinforcing feedback, green = seagrass-algae competition reinforcing feedback, blue $=$ herbivore - algae consumption balancing feedback, yellow $=$ habitat feedback.

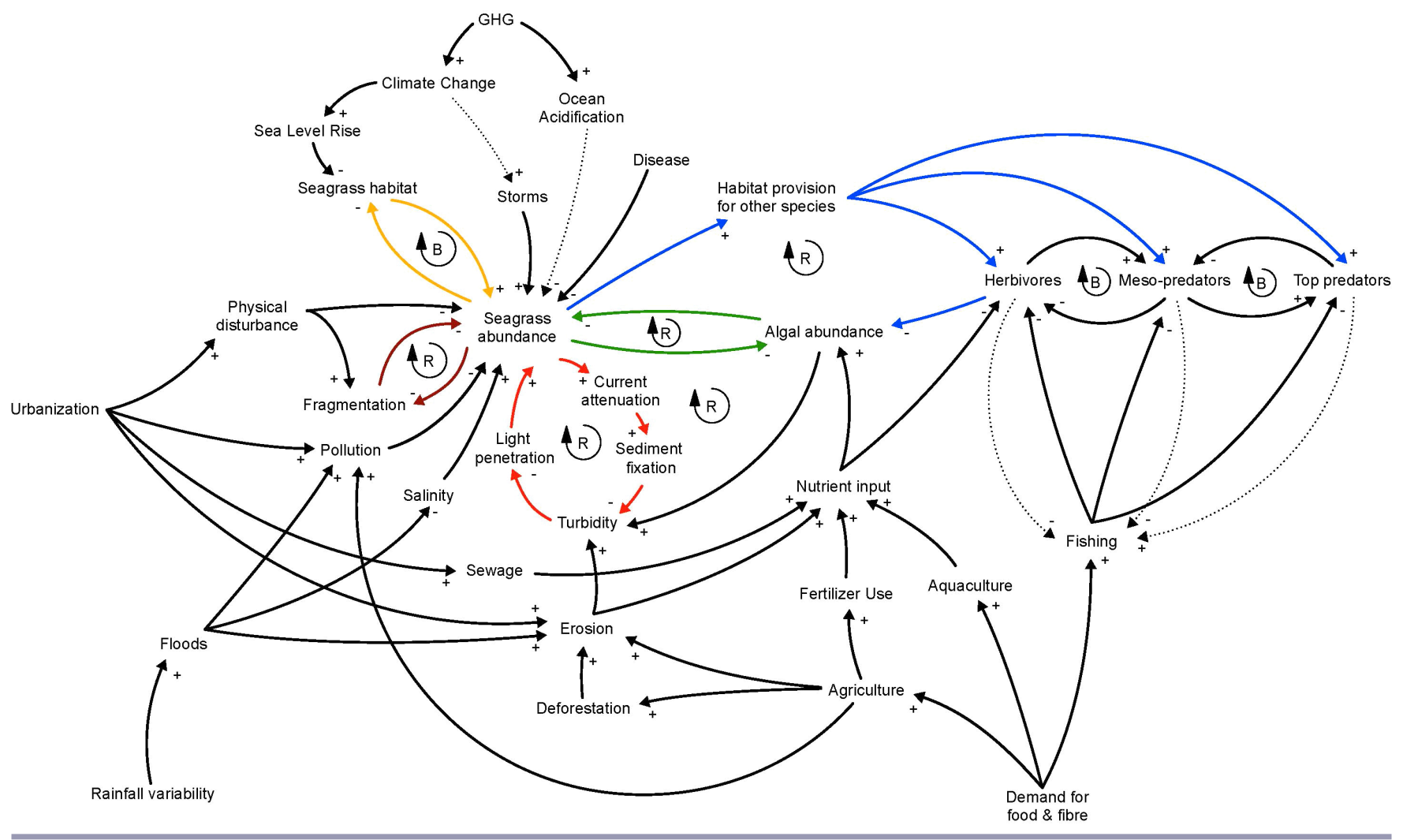

These thresholds correspond to driver levels at which shifts in the dominant feedback processes take place. However, because most regime shifts result from the interplay of multiple drivers, the level of a particular driver at which a regime shift is triggered will depend on the levels of the other key drivers. Consequently, there is usually a whole range of combinations of levels of different drivers that can trigger a particular regime shift. If the shift can happen in two or more directions, the thresholds in relation to each shift are noted.

- Impacts on ecosystem services: A description of the ecosystem processes and services that are lost or gained as a consequence of the regime shift. These include provisioning services such as food or clean water, regulating services such as climate regulation or pollination, and cultural services such as recreation and spiritual values (Millennium Ecosystem Assessment 2005). Impacts on biodiversity or ecosystem functions such as primary production or nutrient cycling are also included.
- Impacts on human well-being: A description of the consequences of changes in ecosystem services for human well-being, where human well-being is seen as encompassing multiple dimensions, including nutrition, health, livelihoods, security, social relations, and freedom of choice (Millennium Ecosystem Assessment 2005). Specific attention is paid to considering which societal groups benefit or lose from particular regime shifts. For this purpose, four archetypal groups are considered: large-scale commercial resource users (e.g., commercial farmers or farming companies, commercial fisherman or companies), small-scale subsistence resource users (e.g., subsistence farmer or fisherman), urban dwellers, and tourists in rural areas. Impacts on other groups in a particular case are also noted where relevant.

- Leverage points and management options: A description of the options for preventing an undesired regime shift or restoring or encouraging a shift to a more desirable regime. A leverage point refers to an SES variable or driver that can be manipulated through a particular management action or 
intervention to bring about larger systemic change. For each leverage point, the scale (local, regional, global) and uncertainty (well established, contested, speculative) is noted, as well as the way in which it influences key drivers and feedback processes to prevent or encourage a shift. Where applicable, differences in management options available to different societal groups are also noted.

- Uncertainties and unresolved issues: Many regime shifts are contested or vary in the extent to which their mechanisms are known. Gaps in knowledge and scientific debates relating to the particular regime shift or case study are identified.

- Key references: Key literature is listed, which readers may refer to for more in-depth information on the particular shift, including literature cited in the narrative descriptions.

The third form of information in the framework is a set of categorical variables that summarizes the information in the narrative descriptions and the CLD. This coding of the information into predefined categories enables simple comparative analyses and provides a mechanism for searching the database in a structured way. For each regime shift, predefined categories are used to summarize: the key direct drivers of the regime shift; the land use and ecosystem type in which the regime shift typically occurs; impacts on key ecosystem processes, biodiversity, ecosystem services (provisioning, regulating, and cultural), and human well-being; the typical spatial and time scales over which the regime shift occurs; and the reversibility of the shift. In addition, information is given on the types of evidence in support of the shift (e.g., observations, models, experiments), and the level of confidence about the existence of the regime shift and the underlying mechanism (speculative, contested, or well established).

Finally, each regime shift contains a list of other regime shifts to which it is connected. For example, marine eutrophication and fisheries collapse are interrelated regime shifts because each can act as a driver of the other. Each regime shift entry is also accompanied by open-source images (diagrams or photographs) illustrating the different regimes. Appendix 2 contains the full data entry template, including the possible options for each categorical variable.

\section{Reflections on applying the regime shift analysis framework}

The students and collaborators who have used the RSDB framework have generally reported finding it very helpful in providing a structured approach to thinking through and developing a deeper understanding of the dynamics underlying regime shifts in the particular examples or cases they were studying. Specific consideration of the alternative regimes, drivers, feedback processes, impacts, and leverage points was found to be very helpful in clarifying and facilitating the analysis of regime shifts compared to less structured approaches. Furthermore, the combination of CLDs, narrative descriptions, and categorical coding was found to be especially helpful in crosschecking the understanding of the regime shift, clarifying system boundaries, distinguishing feedback processes from drivers, and improving consistency within and among regime shifts.
Defining the system boundaries of regime shifts is often difficult, particularly for poorly understood regime shifts. Contributors face the challenge of integrating multiple literature sources and determining which system definitions better match the regime shift dynamics. Slightly different system boundaries lead to different factors being identified as drivers (direct or indirect) and internal or external processes, and can even redefine feedbacks and the characteristic spatial and temporal scales of the regime shift. We found that several controversial regime shifts (e.g., fisheries collapse) have been analyzed using different system boundaries, for example, viewing fishing as an internal variable vs. an external driver of the regime shift. Defining drivers in terms of their proximity to key internal feedback dynamics that underlie the regime shift has not solved the problem but has helped to provide clearer criteria for defining system boundaries.

Distinguishing internal feedback processes from external drivers is a common point of confusion in systems analyses (Sterman 2000, Meadows 2008). The RSDB framework's separate consideration of feedback dynamics and drivers, combined with the development of a CLD, was very helpful in aiding users in making this distinction. Furthermore, requiring that feedbacks and drivers in the CLD be consistent with the narrative text improved both the comprehensiveness and quality of the regime shift descriptions. The categorical variables provided a further check, by ensuring that key variables were included in the analysis, and further helped to increase consistency within and across regime shifts.

To enable comparison among different regime shifts, it is crucial that drivers and feedbacks be defined in a consistent fashion. For example, we had to ensure that "agriculture" was not used as a driver in one regime shift while "fertilizer use" and "land clearing" were used as equivalent drivers in another regime shift. The development of a standard set of variables to be used in the CLDs (Appendix 1) has greatly facilitated consistency, as has the review, by RSDB editors, of all contributions prior to publication online. However, the addition of new regime shifts, especially from new system types, occasionally introduces new processes and drivers not yet captured in this list. Although this has leveled off as the database has grown, maintaining consistency has required periodic revision of the entire database. We expect this iterative process will continue, especially as novel types of regime shifts are added.

\section{EMERGING RESULTS: CURRENT SYNTHESIS OF THE DATABASE}

The RSDB currently contains 28 generic types of regime shift (Table 1), 18 detailed case studies, and 311 basic case studies. These examples have been contributed by $>50$ different people, most of whom are researchers and students at the Stockholm Resilience Centre in Sweden. We next provide a synthesis of the current information and emerging patterns in the database. We focus on the generic regime shifts, and then provide a brief description of the detailed and basic case studies.

\section{Generic types of regime shifts}

For the current RSDB, 10 of the 28 generic regime shifts are well established, both with respect to the existence of regime shifts as well as the underlying mechanism (Fig. 3). A further three examples (forest to savanna, steppe to tundra, and mangrove 
Table 1. Summary of the 28 generic regime shift examples currently in the Regime Shifts Database, organized by system type. Regime 1 typically refers to conditions with limited anthropogenic impacts, whereas Regime 2 usually refers to conditions with extensive anthropogenic impacts.

\begin{tabular}{|c|c|c|c|c|}
\hline System & Number & Regime shift & Regime 1 & Regime 2 \\
\hline \multirow[t]{10}{*}{ Aquatic } & 1 & Freshwater eutrophication & Clear water & Murky water \\
\hline & 2 & Submerged to floating plants & Submerged plant dominance & Floating plant dominance \\
\hline & 3 & Coastal marine eutrophication & Low nutrients & High nutrients \\
\hline & 4 & Hypoxia & Normoxia & Hypoxia, anoxia \\
\hline & 5 & Fisheries collapse & High abundance of commercial fish & Low abundance of commercial fish \\
\hline & 6 & Marine food webs & Predator dominated & Lower trophic group dominated \\
\hline & 7 & Bivalves collapse & High abundance of bivalves & Low abundance of bivalves \\
\hline & 8 & Coral transitions & Coral-dominated reefs & $\begin{array}{l}\text { Macroalgae, soft corals, sponges, } \\
\text { corallimorpharians, urchin barrens }\end{array}$ \\
\hline & 9 & Kelp transitions & Canopy-forming algae & Turf-forming algae, urchin barrens \\
\hline & 10 & Seagrass transitions & Seagrass & Algae dominated or barren sediments \\
\hline & 11 & Soil salinization & Low-salinity soils & High-salinity soils \\
\hline \multirow[t]{5}{*}{ trial } & 12 & Forest to savanna & Forest & Savanna \\
\hline & 13 & Bush encroachment & Grass-dominated savanna & Shrub- or tree-dominated savanna \\
\hline & 14 & Coniferous to deciduous forest & Coniferous forest & Deciduous forest \\
\hline & 15 & Tundra to boreal forest & Tundra & Boreal forest \\
\hline & 16 & Steppe to tundra & Steppe grassland & Tundra \\
\hline \multirow{5}{*}{$\begin{array}{l}\text { Land- } \\
\text { water } \\
\text { interface }\end{array}$} & 17 & Thermokarst lake & Thermokarst lake & Terrestrial ecosystem \\
\hline & 18 & River channel position & Old channel course & New channel course \\
\hline & 19 & Peatland transition & $\begin{array}{l}\text { Low productivity and high carbon } \\
\text { accumulation }\end{array}$ & $\begin{array}{l}\text { High productivity and low carbon } \\
\text { accumulation }\end{array}$ \\
\hline & 20 & Salt marsh to tidal flat & Salt marsh & Tidal or subtidal flat \\
\hline & 21 & Mangrove transition & Mangrove forest & $\begin{array}{l}\text { Ponds, terrestrial systems, settlements, } \\
\text { salt marshes, rocky coasts }\end{array}$ \\
\hline \multirow[t]{5}{*}{ Climate } & 22 & Indian summer monsoon & Strong monsoon & Weak monsoon \\
\hline & 23 & Thermohaline circulation & Strong thermohaline circulation & Collapse of thermohaline circulation \\
\hline & 24 & West Antarctic ice sheet & Permanent ice sheet & No permanent ice sheet \\
\hline & 25 & Greenland ice sheet & Permanent ice sheet & No permanent ice sheet \\
\hline & 26 & Arctic sea-ice loss & Permanent ice sheet & No permanent ice sheet \\
\hline \multirow[t]{2}{*}{ Social } & 27 & Common-pool resource & High cooperation and resource levels & Overharvesting \\
\hline & 28 & Sprawling vs. compact city & Sprawling city & Dense city \\
\hline
\end{tabular}

transitions) are well established in terms of their existence, but the mechanism(s) underlying the regime shift are contested. In general, where the mechanism is not well understood, there is lower confidence about the existence of a regime shift. The most common forms of evidence in support of the regime shifts recorded to date are models (28 regime shifts), paleo-observations (21), and contemporary observations (26), with only 15 regime shifts supported by experimental studies.

More than two-thirds of the regime shifts recorded to date (20 regime shifts) occur at the local or landscape scale, and half (14) of the regime shifts have been reported at subcontinental scale (Fig. 4). In terms of timescales, most regime shifts (25) take place over a period of several years to decades; 9 regime shifts typically take place on shorter time frames of weeks to months, and 7 shifts take place on longer time frames of up to several centuries. These scales are nonexclusive; some regime shifts can occur over several spatial or temporal scales. Twelve of the regime shifts recorded to date are thought to be irreversible on a 100-year timescale, whereas 18 show evidence of hysteresis.
The regime shifts documented to date have been most commonly found in marine and coastal systems (14 regime shifts), followed by freshwater lakes and rivers (7 regime shifts; Fig. 5A). In terms of land uses under which regime shifts occur, fisheries, large-scale commercial crop cultivation, extensive livestock production, conservation, and tourism dominate ( $\geq 8$ regime shifts each). A large number of regime shifts (10) are also recorded in situations in which the land-use impacts are primarily off-site, as in the case of marine eutrophication and transitions from salt marshes to tidal flats. Interestingly, we have recorded relatively few $(\leq 6)$ regime shifts under relatively intensive land uses such as urban, small-scale subsistence agriculture, intensive livestock, timber production, and mining (Fig. 5B).

The RSDB indicates that many different drivers underlie regime shifts. Global climate change, external inputs (e.g., fertilizers, irrigation), environmental shocks (e.g., fire, floods), and harvest and resource consumption are the most common drivers $(\geq 13$ regime shifts each). Global climate change is a contributing driver to 17 of the 28 generic regime shifts currently in the database. The least common drivers reported in the examples to date are adoption of new technologies and disease (Fig. 5C). 
Fig. 3. Level of certainty regarding both the existence of a regime shift and its underlying mechanism for the 28 generic regime shifts currently in the database.

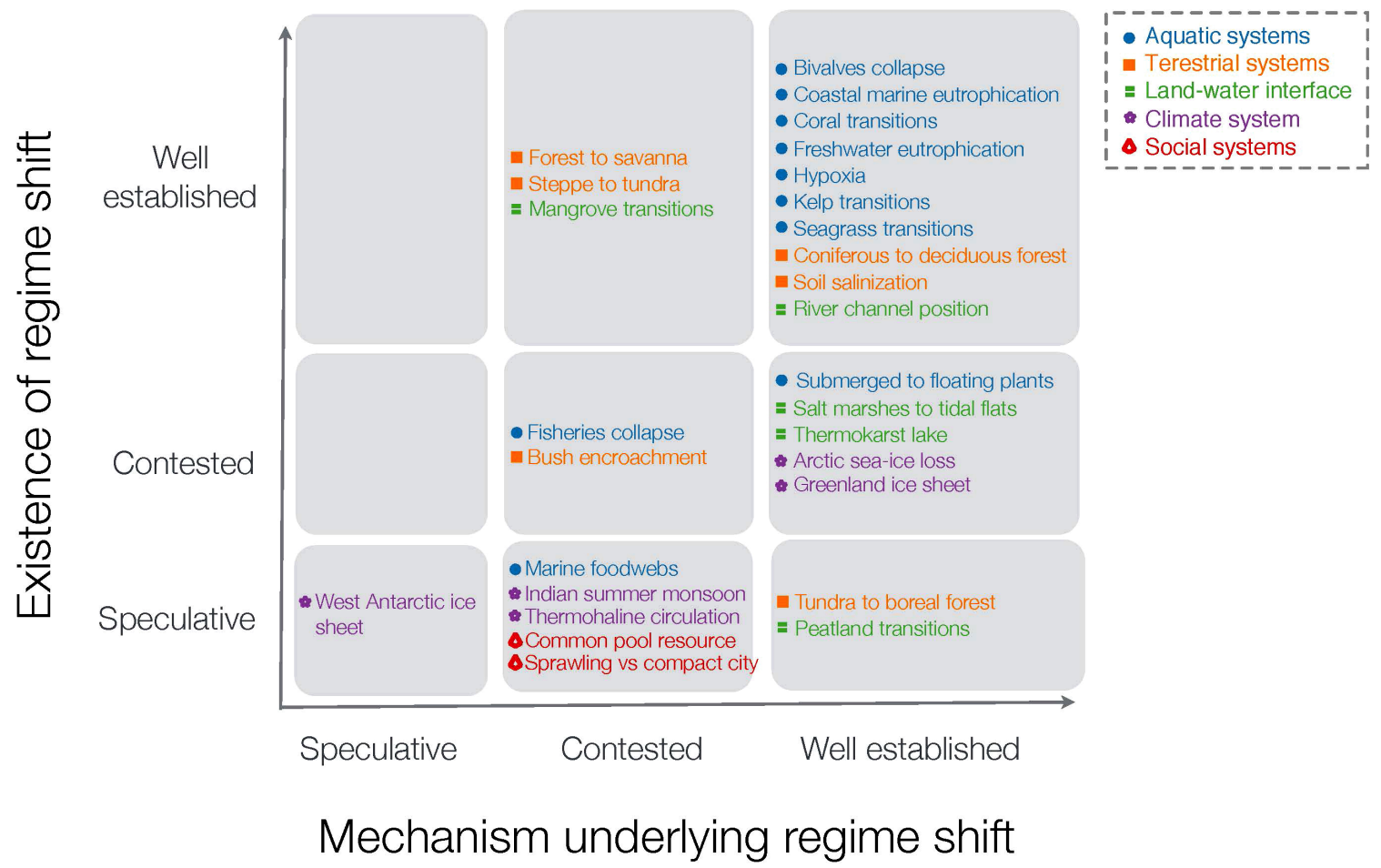

In terms of impacts, biodiversity is affected by all 28 regime shifts (Fig. 6A). The most commonly affected ecosystem processes are primary production (18 regime shifts) and nutrient cycling (17 regime shifts; Fig. 6B). Climate regulation is the regulating service most commonly affected (16), followed by water purification (12; Fig. 6C). In terms of provisioning services, fisheries (20) and wild animal and food products (17) are the most commonly affected (Fig. 6D), and aesthetic values (22) and recreation (20) are the most affected cultural services (Fig. 6E). Translating these effects to impacts on human well-being, livelihoods and economic activity are affected by 26 of the 28 regime shifts, and food and nutrition by 22 regime shifts (Fig. 6F). Cultural, aesthetic, and recreational aspects of human well-being are also commonly affected (19 regime shifts). Aquatic regime shifts tend to cluster in terms of affecting similar ecosystem services and aspects of human well-being (Appendix 3).

\section{Case studies}

To date, only moderate effort has been invested in compiling detailed case studies of regime shifts. When these cases have been undertaken, they typically center on a particular research case that a contributor has the interest to explore in greater depth using the regime shifts analysis framework. Similar to the generic regime shifts, the case study examples are dominated by regime shifts in aquatic systems (11 of the 18 detailed cases). The detailed case studies have also provided a space for conceptual exploration of cases that have not yet been analyzed or framed as regime shifts, for example, the shift in wine production systems in Hungary (http://www.regimeshifts.org/component/k2/item/492-tokaj-wineregionsocialization\#) and rice production systems in Bali (Lansing
2007). Both of these examples are strongly driven by coupled social-ecological dynamics whereby the social variables are not just drivers but also respond adaptively to ecological changes. The vast majority of the basic case studies are examples of hypoxia that were compiled from a comprehensive review paper (Diaz and Rosenberg 2008) as part of a student internship.

\section{DISCUSSION: EMERGING PATTERNS AND RESEARCH AGENDA}

An interest in understanding large, persistent, and often abrupt, systemic change unites researchers working on regime shifts and regime shift-type phenomena. Although such large shifts and reorganization of systems are uncommon, they are important for policy because of the magnitude of their impacts, their unexpected nature, and their persistence (Scheffer et al. 2001, Crépin et al. 2012). The RSDB provides the first consistent, empirically based framework for synthesizing and comparing policy-relevant examples of large, persistent, systemic changes across the ecological, social, and social-ecological literature. The framework can also be applied in contexts in which regime shiftlike phenomena have been observed but not necessarily described using regime shift terminology. In this section, we reflect on what we have learned from application of the framework, discuss emerging patterns from the database, and suggest an agenda for further research.

\section{Emerging patterns}

Several interesting patterns are evident from an initial synthesis of the 28 generic regime shifts that have been captured in the database (Table 1). First, many different regime shifts are 
Fig. 4. The typical spatial and temporal scales of the 28 generic regime shifts currently in the database.

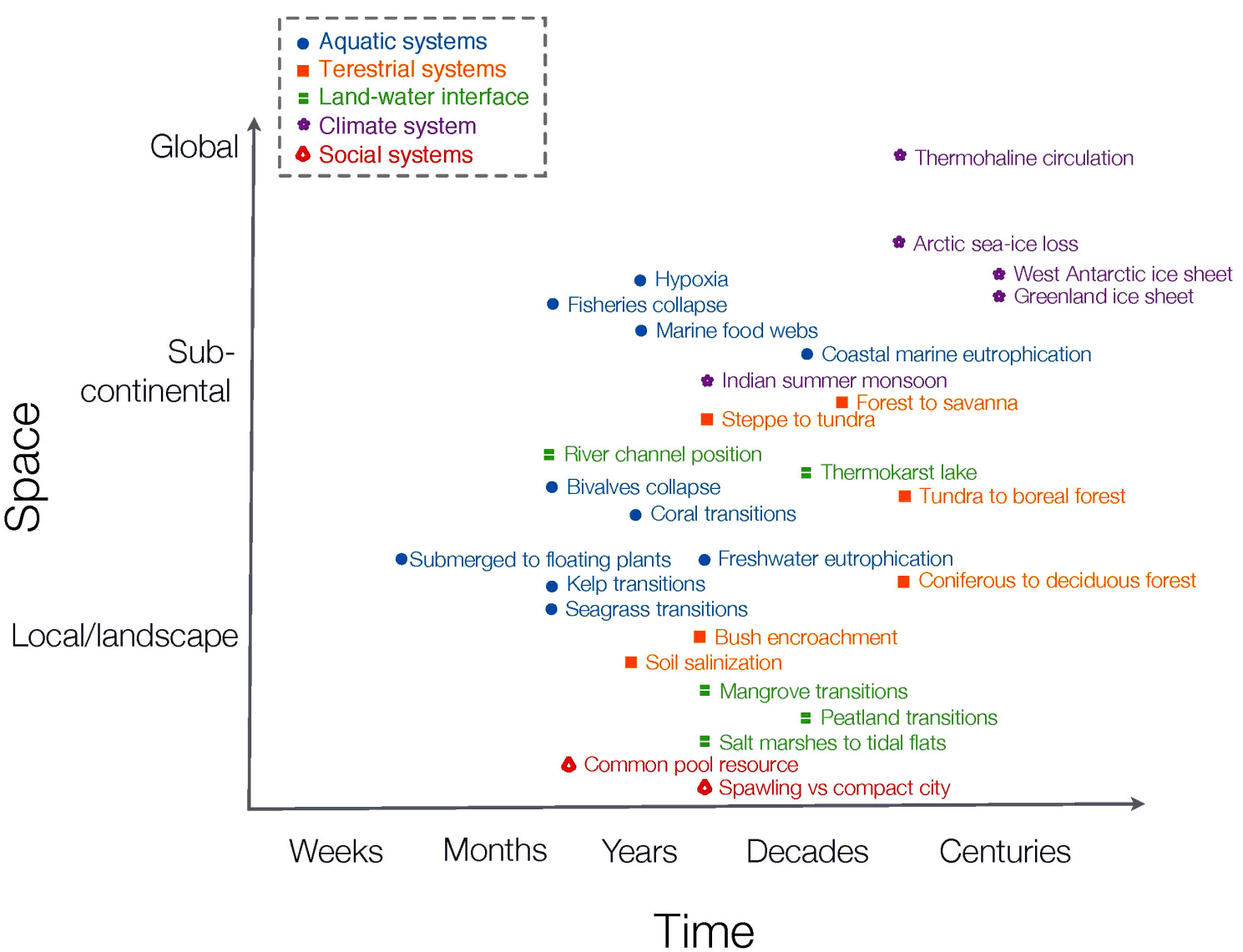

documented in aquatic systems, including freshwater, marine, and coastal ecosystems. Second, climate change plays a pervasive role as a key driver across a wide range of regime shifts. Third, there is a substantial impact of regime shifts on biodiversity and fisheries. Fourth, there are surprisingly large impacts on cultural ecosystem services and key aspects of human well-being.

There are three alternative explanations for the high number of regime shifts in aquatic systems (Fig. 5A): there has been more research in aquatic systems, aquatic systems are more affected because most people live near water, or aquatic environments are more susceptible to regime shifts. These are explanations are not mutually exclusive, and there is evidence to support all three explanations to some degree. A bibliographic analysis has shown that there are more publications on regime shifts in aquatic systems than in other systems (Rocha 2015). More than $50 \%$ of the world's population lives $<3 \mathrm{~km}$ from a surface freshwater body, and only $10 \%$ of the population lives $>10 \mathrm{~km}$ away (Kummu et al. 2011). Similarly, approximately $40 \%$ of the global population and two-thirds of the world's major cities are located within $100 \mathrm{~km}$ of the ocean (Kummu et al. 2016). At the same time, seminal theoretical papers on regime shifts suggest that regime shifts were more likely to be observed in semi-enclosed systems such as lakes (Holling 1973). Distinguishing the contribution of these explanations should be a goal of future research.

Climate change has been identified as a contributing driver in almost two-thirds of the regime shifts captured to date, and environmental shocks such as droughts and floods are a driver in almost one-half of the recorded regime shifts (Fig. 5C). The prominence of climate change, together with agriculture-related activities, was also identified in earlier, more detailed analyses of regime shift drivers based on the RSDB (Rocha et al. 2015b). The importance of climate change is related to the primary importance of temperature and precipitation in governing terrestrial ecosystem dynamics, especially the flow of energy and materials (Chapin et al. 2011), and similarly, is related to the role of temperature, sea level, and storms in governing marine and coastal ecosystem dynamics (Mann and Lazier 2006, Barange et al. 2010). The importance of climate change, together with agriculture-related activities (e.g., inputs of fertilizers), suggests that the incidence of a wide range of regime shifts is likely to increase in future.

Biodiversity is substantively affected by all regime shifts analyzed to date (Fig. 6A), including the two shifts that are driven primarily by changed feedbacks in the social domain (Table 1). This is directly related to the fact that regime shifts, as defined here, entail 
Fig. 5. Number of regime shifts recorded in different ecosystem types (A) and land uses (B), and the key drivers of these regime shifts (C). The figure is based on the 28 generic regime shifts currently in the database.

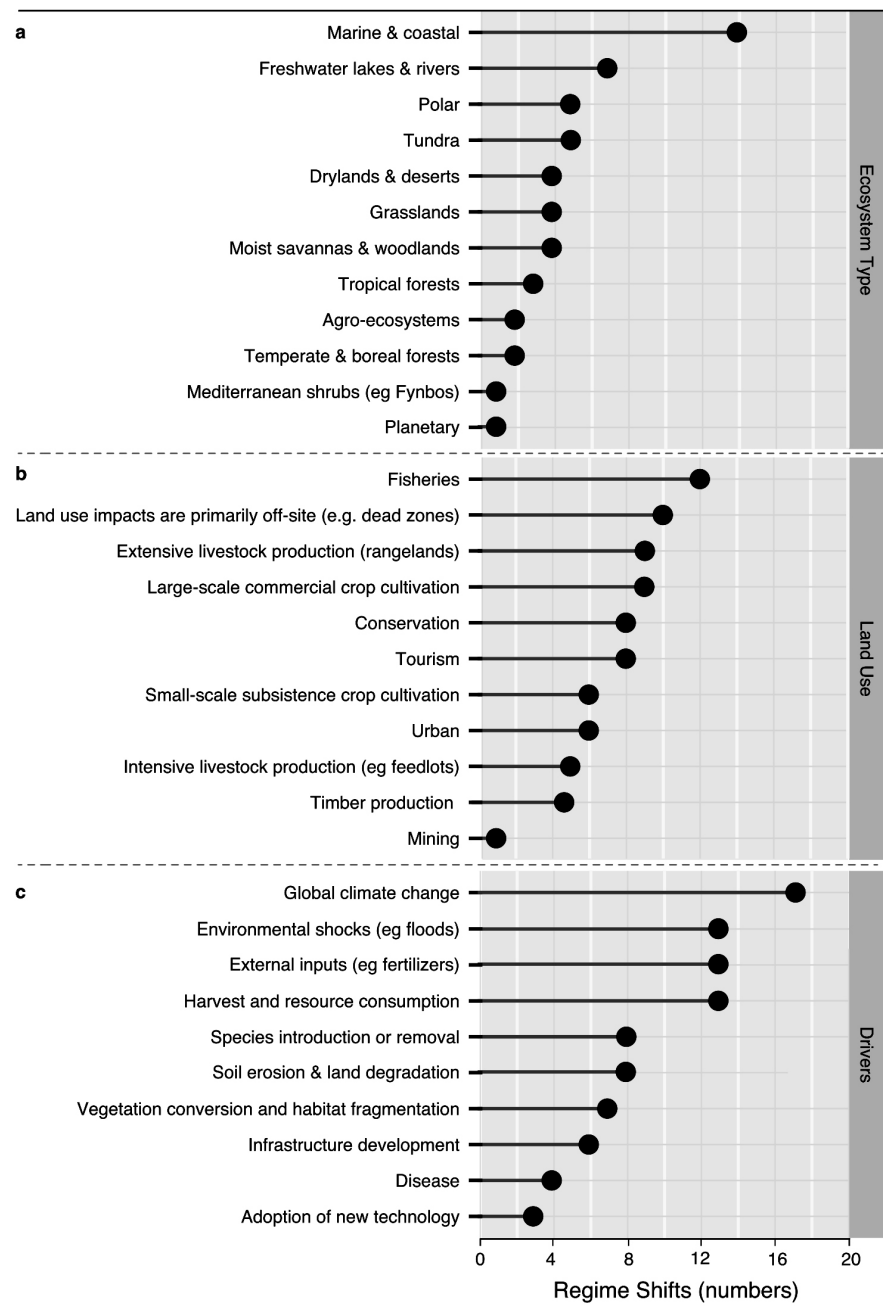

a substantial change in system structure and function, and therefore, have direct consequences for species composition and community assemblages, as well as potential consequences for diversity at genetic and ecosystem levels (Leadley et al. 2014). The substantial impact on fisheries (Fig. 6D) is directly related to the prevalence of regime shifts in aquatic systems (marine, coastal, and freshwater lakes and rivers; Fig. 5A). The increasing likelihood of regime shifts because of ongoing increases in most key drivers of regime shifts (Fig. 5C) suggests that projected declines in biodiversity in the 21 st century (Pereira et al. 2010) may be further exacerbated.

Our results show unexpectedly large effects on aesthetic and recreation-related cultural ecosystem services (Fig. 6E). Whereas regime shifts have frequently been identified as affecting provisioning and regulating ecosystem services, impacts on cultural services often receive less attention (Millennium Ecosystem
Fig. 6. Number of regime shifts that affect biodiversity (A), ecosystem processes (B), regulating services (C), provisioning services (D), cultural services (E), and human well-being (F). The figure is based on the 28 generic regime shifts currently in the database.

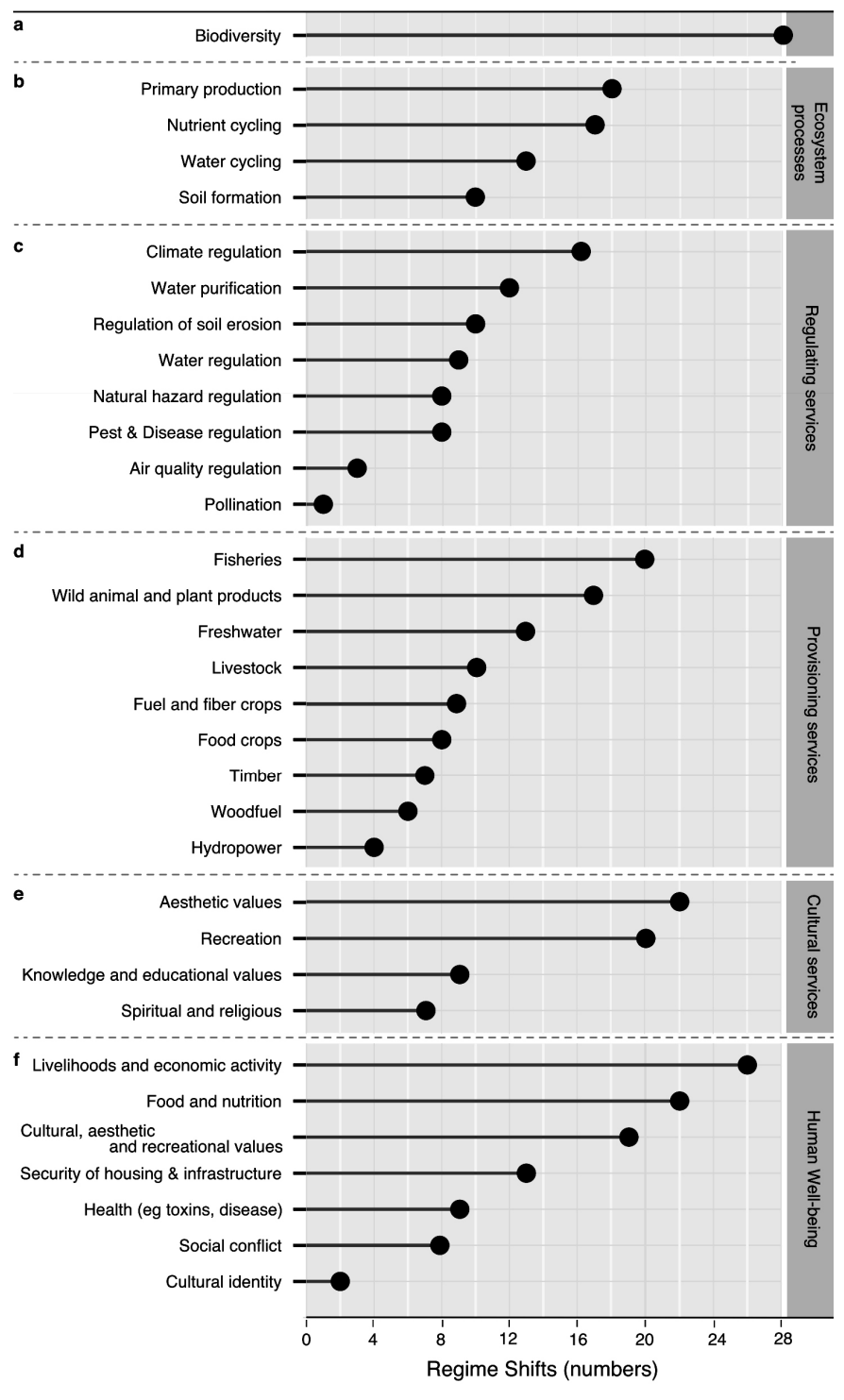

Assessment 2005). Our findings suggest that regime shift research should pay more attention to impacts on cultural services, and assessments of cultural ecosystem services should consider the possibility of regime shifts. Our results further show that there are substantial impacts on key aspects of human well-being, specifically on livelihoods and economic activity; food and nutrition; and cultural, aesthetic, and recreational values (Fig. 6F). These findings suggest that the increasing likelihood of regime shifts is likely to complicate efforts to reduce poverty and human deprivation in relation to national and global efforts to achieve targets such as sustainable development goals (http://www.un.org/sustainabledevelopment/ sustainable-development-goals). 


\section{Comparative analyses}

The main contribution of the RSDB is that it provides a platform for a wide range of comparative analyses such as comparisons across ecosystem types, regions, drivers, feedbacks, or regime shift impacts. The information in the database has been used by numerous Masters and Doctoral students to analyze various cross-cutting patterns (dissertations available at http://www. regimeshifts.org), as well as in a resilience assessment of the Arctic (Carson and Peterson 2016).

For example, Rocha et al. (2015a) has used the RSDB to conduct a comparison of the drivers and ecosystem service impacts of marine regime shifts. Their study confirms the patterns reported here for a subset of marine regime shifts and stresses the importance of managing drivers that are likely to increase, especially in places where monitoring programs might not be implemented. A global analysis of regime shifts drivers based on the RSDB suggests that two-thirds of the drivers can be managed at local to regional scales, but without international cooperation, preventing undesired regime shifts is a difficult endeavor (Rocha et al. 2015b). In this regard, an important area of future research is investigating the mismatch between governance systems and regime shifts dynamics.

Hammond (2012) conducted an exploratory study of the impacts of agriculturally driven regime shifts on ecosystem services and human well-being and found that the impacts of regime shifts are highly differentiated among different social groups. Furthermore, her analysis suggests that the actors whose activities are largely responsible for the increased incidence of regime shifts (in this case, large commercial farming enterprises) are the sector least affected by the changes in ecosystem services associated with the regime shift. In contrast, marginalized actors with relatively small contributions to the regime shifts often bear the brunt of the impacts. Her conclusions highlight the importance of differentiating the effects on different social groups in future regime shifts analyses.

Also possible are comparative analyses of the structure of regime shifts such as analyses of the patterns of regime shift drivers or feedback dynamics. For example, Tshimpanga (2012) used the RSDB framework to analyze poverty traps in sub-Saharan Africa and identified key feedbacks and potential leverage points to escape from such traps. Sadauskis (2011) analyzed the feedback structure of climate-driven regime shifts to investigate local to regional options for building resilience to climate change, for instance, through managing forest cover. Such exploratory analyses could be deepened and expanded to other regions, contexts, and questions.

The database has also provided inputs to international environmental assessments. Peterson and Rocha (2016) conducted a comparative analysis of regime shifts in the Arctic for the Arctic resilience assessment (Carson and Peterson 2016). They found that Arctic regime shifts are typically driven by climate change, but they also affect feedbacks that destabilize climate regulation. This means that the Arctic is a region of the world that is particularly prone to cascading effects or the likelihood of interconnected regime shift dynamics. How and when these cascading effects are likely to occur is a key question for future research. As part of the same assessment, Huitric et al. (2016) used a modified version of the RSDB template to capture how
Arctic communities are dealing with change, both ecological regime shifts and unfolding social and political pressures. Their analysis highlighted the role of self-organization as a key source of adaptive capacity and resilience in the region.

These examples show how the database can be a useful resource for integrative science efforts such as IPBES, Future Earth, or the Program on Ecosystem Change and Society. It also shows how the structure of the database and its template can be tailored to address specific research questions, including potentially addressing those identified for advancing the understanding of land-use regime shifts (Ramankutty and Coomes 2016) or sustainability transformations (Olsson et al. 2014), or for the application of network theory to ecosystem service assessments (Bodin et al. 2017, Dee et al. 2017).

\section{An agenda for regime shift research}

The RSDB highlights that regime shifts are currently unevenly and incompletely studied in terms of their consequences for human well-being. A few regime shifts such as eutrophication in lakes, coral reefs, and hypoxia have been extensively studied. However, many regime shifts such as river channel position and marine food webs have only been studied in a few places, while the understanding about potentially highly significant regime shifts such as collapse of the West Antarctic ice sheet remains speculative. Furthermore, where regime shift studies have been undertaken, they often pay little attention to effects on ecosystem services, especially cultural services, and the consequences for human well-being. More research is needed to understand the different combinations of drivers and potential pathways that may lead to particular regime shifts. In addition, to inform policy and governance, regime shift studies need to pay specific attention to illuminating the consequences of regime shifts for different types of ecosystem services, their implications for multiple aspects of human well-being, and how these effects vary among different societal groups.

An emerging and particularly understudied area of research is how regime shift dynamics with important consequences for ecosystem services arise from social feedbacks or the interaction of social and ecological processes (rather than from purely ecological feedbacks). For example, Lade et al. (2013) used a modeling approach to demonstrate that overharvesting and collapse of a common-pool resource can arise from the interaction of ecological dynamics and social norms that regulate harvesting levels, but does not arise if only the social or only the ecological dynamics are considered. Understanding human actions as both a driver and a feedback of regime shifts is a challenging task. To date, there is little understanding of which social feedbacks are strong and stable enough over time to maintain different social-ecological regimes or where they are better regarded as sources of noise at the timescales at which ecosystem dynamics occur. This lack of understanding is especially the case in cross-scale processes such as trade and migration (Adger et al. 2009) or where management involves learning or adaptive policy change (Peterson et al. 2003). As global trade and markets demand different standards and products or new forms of communication technology strengthen connections between distant places, do these create new socialecological regimes or simply modify and increase the variability of existing regimes? 
We suggest that new conceptual models and methods are needed to address these novel social dynamics and social-ecological interactions and represent them in social-ecological regime shift analyses. The RSDB framework can be used to support this endeavor. Examples of key conceptual questions that could be illuminated by comparative analyses of the examples in the database include: How can social-ecological regime shifts be usefully defined as distinct from strictly ecological regime shifts? Can the concept of regime shifts be usefully applied to systems strongly shaped by unstable telecouplings and teleconnections? Such analyses could also help to understand better the contexts in which a regime shift framework is useful for understanding dynamics of change, and situations in which it is perhaps less useful or needs to be complemented by other frameworks or perspectives.

\section{CONCLUSION}

The RSDB provides a framework for synthesizing knowledge that is dispersed across the social and natural sciences on a diverse set of policy-relevant large, systemic changes that hold substantive implications for ecosystem services and human well-being. By documenting diverse regime shifts in a consistent way, the database provides a novel platform for comparison of drivers, feedback processes, impacts, and potential management options. Such information can help to identify parts of world where different regime shifts are more likely to occur and to highlight the potential consequences of possible regime shifts. Comparative analyses across different regime shifts could also help to identify the major regional and global drivers of regime shifts and potential leverage points for reducing vulnerability to multiple regime shifts simultaneously to reduce the risk of cascading sets of regime shifts. In addition to these direct policy-relevant insights, the RSDB provides a platform for generating new conceptual advances in understanding the dynamics of regime shifts, and social-ecological regime shifts in particular.

Managing systems subject to regime shifts requires quite different approaches than situations in which change is predictable and reversible (Carpenter 2003). The diversity of examples already in the database suggests that the possibility of large, abrupt, systemic changes should probably be more widely considered in environmental management and assessment than it currently is. Our emerging findings further suggest that projections of the future that do not consider the possibility of abrupt change are likely to systematically underestimate the impacts of environmental change. We hope that the RSDB can provide a useful resource for global and regional environmental assessments such as IPBES to better incorporate knowledge and understanding that already exists, to facilitate greater consideration of regime shift dynamics in policy and practice, and ultimately, to enhance our collective ability to manage and govern large, abrupt, systemic changes that are likely to become increasingly prevalent in the Anthropocene.

Responses to this article can be read online at: http://www.ecologyandsociety.org/issues/responses. $\mathrm{php} / 10264$

\section{Acknowledgments:}

We sincerely thank the many contributors (listed at www. regimeshifts.org) that have added and reviewed examples for the database, as well as colleagues who gave input and feedback on the database design. We also gratefully acknowledge funding sources that supported the authors and the development of the online platform: the Swedish Foundation for Strategic Environmental Research (MISTRA); the Swedish Research Council (grant 621-2014-5137); the Swedish Research Council Formas (grant 2009-1333); a Branco Weiss Society in Science Fellowship; the GRAID project funded by the Swedish International Development Agency (SIDA); and the South African Research Chairs Initiative (SARChI) of the Department of Science and Technology and National Research Foundation of South Africa (grant 98766). Two reviewers also provided helpful comments.

\section{LITERATURE CITED}

Adger, W. N., H. Eakin, and A. Winkels. 2009. Nested and teleconnected vulnerabilities to environmental change. Frontiers in Ecology and the Environment 7(3):150-157. http://dx.doi. org/10.1890/070148

Anderies, J. M., P. Ryan, and B. H. Walker. 2006. Loss of resilience, crisis, and institutional change: lessons from an intensive agricultural system in southeastern Australia. Ecosystems 9(6):865-878. http://dx.doi.org/10.1007/s10021-006-0017-1

Andersen, T., J. Carstensen, E. Hernández-García, and C. M. Duarte. 2009. Ecological thresholds and regime shifts: approaches to identification. Trends in Ecology and Evolution 24(1):49-57. http://dx.doi.org/10.1016/j.tree.2008.07.014

Barange, M., J. G. Field, R. P. Harris, E. E. Hofmann, R. I. Perry, and F. Werner, editors. 2010. Marine ecosystems and global change. Oxford University Press, Oxford, UK. http://dx.doi.org/10.1093/ acprof:oso/9780199558025.001.0001

Barnosky, A. D., E. A. Hadly, J. Bascompte, E. L. Berlow, J. H. Brown, M. Fortelius, W. M. Getz, J. Harte, A. Hastings, P. A. Marquet, N. D. Martinez, A. Mooers, P. Roopnarine, G. Vermeij, J. W. Williams, R. Gillespie, J. Kitzes, C. Marshall, N. Matzke, D. P. Mindell, E. Revilla, and A. B. Smith. 2012. Approaching a state shift in Earth's biosphere. Nature 486(7401):52-58. http://dx.doi. org/10.1038/nature11018

Bennett, E. M., G. S. Cumming, and G. D. Peterson. 2005. A systems model approach to determining resilience surrogates for case studies. Ecosystems 8(8):945-957. http://dx.doi.org/10.1007/ $\underline{\mathrm{s} 10021-005-0141-3}$

Biggs, R., T. Blenckner, C. Folke, L. J. Gordon, A. Norström, M. Nyström, and G. D. Peterson. 2012. Regime shifts. Pages 609-617 in A. Hastings and L. J. Gross, editors. Encyclopedia of theoretical ecology. University of California Press, Berkeley, California, USA.

Biggs, R., S. R. Carpenter, and W. A. Brock. 2009. Turning back from the brink: detecting an impending regime shift in time to avert it. Proceedings of the National Academy of Sciences 106 (3):826-831. http://dx.doi.org/10.1073/pnas.0811729106 
Biggs, R., M. Schlüter, and M. L. Schoon, editors. 2015. Principles for building resilience: sustaining ecosystem services in socialecological systems. Cambridge University Press, Cambridge, UK. http://dx.doi.org/10.1017/CBO9781316014240

Bodin, Ö., M. L. Barnes, R. R. J. McAllister, J. C. Rocha, and A. M. Guerrero. 2017. Social-ecological network approaches in interdisciplinary research: a response to Bohan et al. and Dee et al. Trends in Ecology and Evolution 32(8):547-549. http://dx.doi. org/10.1016/j.tree.2017.06.003

Carpenter, S. R. 2003. Regime shifts in lake ecosystems: pattern and variation. International Ecology Institute, Oldendorf/Luhe, Germany.

Carpenter, S. R., H. A. Mooney, J. Agard, D. Capistrano, R. S. DeFries, S. Díaz, T. Dietz, A. K. Duraiappah, A. Oteng-Yeboah, H. M. Pereira, C. Perrings, W. V. Reid, J. Sarukhan, R. J. Scholes, and A. Whyte. 2009. Science for managing ecosystem services: beyond the Millennium Ecosystem Assessment. Proceedings of the National Academy of Sciences 106(5):1305-1312. http://dx. doi.org/10.1073/pnas.0808772106

Carson, M., and G. Peterson, editors. 2016. Arctic resilience report. Arctic Council, Stockholm Environment Institute and Stockholm Resilience Centre, Stockholm, Sweden. [online] URL: https://www.sei.org/publications/arctic-resilience-report/

Chapin, F. S. III, P. A. Matson, and P. M. Vitousek. 2011. Principles of terrestrial ecosystem ecology. Springer, New York, New York, USA. http://dx.doi.org/10.1007/978-1-4419-9504-9

Checkland, P., and J. Poulter. 2006. Learning for action: a short definitive account of soft systems methodology and its use for practitioners, teachers and students. Wiley, Chichester, UK.

Conversi, A., V. Dakos, A. Gårdmark, S. Ling, C. Folke, P. J. Mumby, C. Greene, M. Edwards, T. Blenckner, M. Casini, A. Pershing, and C. Möllmann. 2014. A holistic view of marine regime shifts. Philosophical Transactions of the Royal Society B: Biological Sciences 370(1659):20130279. http://dx.doi.org/10.1098/ $\underline{\text { rstb.2013.0279 }}$

Crépin, A.-S., R. Biggs, S. Polasky, M. Troell, and A. de Zeeuw. 2012. Regime shifts and management. Ecological Economics 84:15-22. https://doi.org/10.1016/j.ecolecon.2012.09.003

Dee, L. E., S. Allesina, A. Bonn, A. Eklöf, S. D. Gaines, J. Hines, U. Jacob, E. McDonald-Madden, H. Possingham, M. Schröter, and R. M. Thompson. 2017. Operationalizing network theory for ecosystem service assessments. Trends in Ecology \& Evolution 32 (2):118-130. http://dx.doi.org/10.1016/j.tree.2016.10.011

Diaz, R. J., and R. Rosenberg. 2008. Spreading dead zones and consequences for marine ecosystems. Science 321(5891):926-929. http://dx.doi.org/10.1126/science.1156401

Gordon, L. J., G. D. Peterson, and E. M. Bennett. 2008. Agricultural modifications of hydrological flows create ecological surprises. Trends in Ecology and Evolution 23(4):211-219. http:// dx.doi.org/10.1016/j.tree.2007.11.011

Hammond, C. 2012. Impacts of agriculturally-driven regime shifts on ecosystem services and human well-being. Thesis. Stockholm University, Stockholm, Sweden. [online] URL: http://su.divaportal.org/smash/get/diva2:532765/FULLTEXT01
Holling, C. S. 1973. Resilience and stability of ecological systems. Annual Review of Ecology and Systematics 4:1-23. http://dx.doi. org/10.1146/annurev.es.04.110173.000245

Hughes, T. P., S. Carpenter, J. Rockström, M. Scheffer, and B. Walker. 2013a. Multiscale regime shifts and planetary boundaries. Trends in Ecology and Evolution 28(7):389-395. https://doi.org/10.1016/j.tree.2013.05.019

Hughes, T. P., C. Linares, V. Dakos, I. A. van de Leemput, and E. H. van Nes. 2013b. Living dangerously on borrowed time during slow, unrecognized regime shifts. Trends in Ecology and Evolution 28(3):149-155. https://doi.org/10.1016/j.tree.2012.08.022

Huitric, M., G. Peterson, and J. C. Rocha. 2016. What factors build or erode resilience in the Arctic? Pages 96-125 in M. Carson and G. Peterson, editors. Arctic resilience report. Stockholm Environment Institute and Stockholm Resilience Centre, Stockholm, Sweden. [online] URL: https://www.sei.org/ mediamanager/documents/Publications/ArcticResilienceReport-2016. pdf

Kummu, M., H. de Moel, G. Salvucci, D. Viviroli, P. J. Ward, and O. Varis. 2016. Over the hills and further away from coast: global geospatial patterns of human and environment over the 20th-21st centuries. Environmental Research Letters 11(3):034010. https:// doi.org/10.1088/1748-9326/11/3/034010

Kummu, M., H. de Moel, P. J. Ward, and O. Varis. 2011. How close do we live to water? A global analysis of population distance to freshwater bodies. Plos One 6(6):e20578. http://dx.doi. org/10.1371/journal.pone.0020578

Lade, S. J., A. Tavoni, S. A. Levin, and M. Schlüter. 2013. Regime shifts in a social-ecological system. Theoretical Ecology 6 (3):359-372. http://dx.doi.org/10.1007/s12080-013-0187-3

Lane, D. C. 2008. The emergence and use of diagramming in system dynamics: a critical account. Systems Research and Behavioral Science 25(1):3-23. http://dx.doi.org/10.1002/sres.826

Lansing, J. S. 2007. Priests and programmers: technologies of power in the engineered landscape of Bali. Princeton University Press, Princeton, New Jersey, USA.

Leadley, P., V. Proença, J. Fernández-Manjarrés, H. M. Pereira, R. Alkemade, R. Biggs, E. Bruley, W. Cheung, D. Cooper, J. Figueiredo, E. Gilman, S. Guénette, G. Hurtt, C. Mbow, T. Oberdorff, C. Revenga, J. P. W. Scharlemann, R. Scholes, M. Stafford Smith, U. R. Sumaila, and M. Walpole. 2014. Interacting regional-scale regime shifts for biodiversity and ecosystem services. Bioscience 64(8):665-679. https://doi.org/10.1093/biosci/ $\underline{\text { biu093 }}$

Lees, K., S. Pitois, C. Scott, C. Frid, and S. Mackinson. 2006. Characterizing regime shifts in the marine environment. Fish and Fisheries 7(2):104-127. http://dx.doi.org/10.1111/j.1467-2979.2006.00215. $\underline{\mathrm{x}}$

Lenton, T. M. 2013. Environmental tipping points. Annual Review of Environment and Resources 38:1-29. http://dx.doi.org/10.1146/ annurev-environ-102511-084654

Lenton, T. M., H. Held, E. Kriegler, J. W. Hall, W. Lucht, S. Rahmstorf, and H. J. Schellnhuber. 2008. Tipping elements in the Earth's climate system. Proceedings of the National Academy of Sciences 105(6):1786-1793. http://dx.doi.org/10.1073/pnas.0705414105 
Levin, S., T. Xepapadeas, A.-S. Crépin, J. Norberg, A. de Zeeuw, C. Folke, T. Hughes, K. Arrow, S. Barrett, G. Daily, P. Ehrlich, N. Kautsky, K.-G. Mäler, S. Polasky, M. Troell, J. R. Vincent, and B. Walker. 2013. Social-ecological systems as complex adaptive systems: modeling and policy implications. Environment and Development Economics 18(2):111-132. http://dx.doi.org/10.1017/ $\underline{\mathrm{S} 1355770 \mathrm{X} 12000460}$

Mann, K. H., and J. R. N. Lazier. 2006. Dynamics of marine ecosystems: biological-physical interactions in the oceans. Third edition. Blackwell, Malden, Massachusetts, USA. http://dx.doi. org/10.1002/9781118687901

Mård Karlsson, J., A. Bring, G. D. Peterson, L. J. Gordon, and G. Destouni. 2011. Opportunities and limitations to detect climate-related regime shifts in inland Arctic ecosystems through eco-hydrological monitoring. Environmental Research Letters 6 (1):014015. http://dx.doi.org/10.1088/1748-9326/6/1/014015

Meadows, D. H. 2008. Thinking in systems: a primer. Chelsea Green Publishing, White River Junction, Vermont, USA.

Millennium Ecosystem Assessment. 2005. Ecosystems and human well-being: synthesis. Island Press, Washington, D.C., USA.

Nelson, G. C., E. Bennett, A. A. Berhe, K. Cassman, R. DeFries, T. Dietz, A. Dobermann, A. Dobson, A. Janetos, M. Levy, D. Marco, N. Nakicenovic, B. O’Neill, R. Norgaard, G. PetschelHeld, D. Ojima, P. Pingali, R. Watson, and M. Zurek. 2006. Anthropogenic drivers of ecosystem change: an overview. Ecology and Society 11(2):29. http://dx.doi.org/10.5751/ ES-01826-110229

Nyström, M., A. V. Norström, T. Blenckner, M. de la TorreCastro, J. S. Eklöf, C. Folke, H. Österblom, R. S. Steneck, M. Thyresson, and M. Troell. 2012. Confronting feedbacks of degraded marine ecosystems. Ecosystems 15(5):695-710. http:// dx.doi.org/10.1007/s10021-012-9530-6

Olsson, P., V. Galaz, and W. J. Boonstra. 2014. Sustainability transformations: a resilience perspective. Ecology and Society 19 (4):1. http://dx.doi.org/10.5751/ES-06799-190401

Pereira, H. M., P. W. Leadley, V. Proença, R. Alkemade, J. P. W. Scharlemann, J. F. Fernandez-Manjarrés, M. B. Araújo, P. Balvanera, R. Biggs, W. W. L. Cheung, L. Chini, H. D. Cooper, E. L. Gilman, S. Guénette, G. C. Hurtt, H. P. Huntington, G. M. Mace, T. Oberdorff, C. Revenga, P. Rodrigues, R. J. Scholes, U. R. Sumaila, and M. Walpole. 2010. Scenarios for global biodiversity in the 21 st century. Science 330:1496-1501. http://dx. doi.org/10.1126/science.1196624

Peterson, G., and J. C. Rocha. 2016. Arctic regime shifts and resilience. Pages 64-95 in M. Carson and G. Peterson, editors. Arctic resilience report. Stockholm Environment Institute and Stockholm Resilience Centre, Stockholm, Sweden. [online] URL: https://www.sei.org/publications/arctic-resilience-report/

Peterson, G. D., S. R. Carpenter, and W. A. Brock. 2003. Uncertainty and the management of multistate ecosystems: an apparently rational route to collapse. Ecology 84(6):1403-1411. https://doi.org/10.1890/0012-9658(2003)084[1403:UATMOM]2.0. $\mathrm{CO} ; 2$
Ramankutty, N., and O. T. Coomes. 2016. Land-use regime shifts: an analytical framework and agenda for future land-use research. Ecology and Society 21(2):1. http://dx.doi.org/10.5751/ES-08370-210201

Reid, W. V., D. Chen, L. Goldfarb, H. Hackmann, Y. T. Lee, K. Mokhele, E. Ostrom, K. Raivio, J. Rockström, H. J. Schellnhuber, and A. Whyte. 2010. Earth system science for global sustainability: grand challenges. Science 330(6006):916-917. http://dx.doi.org/10.1126/science.1196263

Resilience Alliance. 2007. Assessing and managing resilience in social-ecological systems: a practitioner's workbook. Resilience Alliance. [online] URL: https://www.resalliance.org/resilienceassessment

Reyers, B., C. Folke, M.-L. Moore, R. Biggs, and V. Galaz. 2018. Social-ecological systems insights for navigating the dynamics of the Anthropocene. Annual Review of Environment and Resources 43, in press.

Rocha, J., J. Yletyinen, R. Biggs, T. Blenckner, and G. Peterson. 2015a. Marine regime shifts: drivers and impacts on ecosystems services. Philosophical Transactions of the Royal Society B: Biological Sciences 370(1659):20130273. http://dx.doi.org/10.1098/ rstb.2013.0273

Rocha, J. C. 2015. Regime shifts in the Anthropocene. Dissertation. Stockholm University, Stockholm, Sweden. [online] URL: https://www.diva-portal.org/smash/get/diva2:809637/FULLTEXT01. pdf

Rocha, J. C., G. D. Peterson, and R. Biggs. 2015b. Regime shifts in the Anthropocene: drivers, risks, and resilience. Plos One 10(8): e0134639. https://doi.org/10.1371/journal.pone.0134639

Sadauskis, R. 2011. Building resilience to climate-driven regime shifts. Thesis. Stockholm University, Stockholm, Sweden.

Scheffer, M. 2009. Critical transitions in nature and society. Princeton University Press, Princeton, New Jersey, USA.

Scheffer, M., S. Carpenter, J. A. Foley, C. Folke, and B. Walker. 2001. Catastrophic shifts in ecosystems. Nature 413:591-596. http://dx.doi.org/10.1038/35098000

Schindler, D. W. 2006. Recent advances in the understanding and management of eutrophication. Limnology and Oceanography 51 (1):356-363. http://dx.doi.org/10.4319/10.2006.51.1 part 2.0356

Staver, A. C., S. Archibald, and S. A. Levin. 2011. The global extent and determinants of savanna and forest as alternative biome states. Science 334:230-232. http://dx.doi.org/10.1126/ science. 1210465

Sterman, J. D. 2000. Business dynamics: systems thinking and modeling for a complex world. McGraw-Hill/Irwin, New York, New York, USA.

Tshimpanga, J. M. 2012. A regime shift analysis of poverty traps in sub-Saharan Africa: identifying key feedbacks and leverage points for change. Thesis. Uppsala University, Uppsala, Sweden. [online] URL: http://www.diva-portal.se/smash/get/diva2:482021/ FULLTEXT01.pdf

Walker, B. H., and J. A. Meyers. 2004. Thresholds in ecological and social-ecological systems: a developing database. Ecology and Society 9(2):3. [online] URL: http://www.ecologyandsociety.org/ vol9/iss $2 /$ art $3 /$ 
Appendix 1. Standardized list of drivers used in the Regime Shifts Database

(RSDB). Drivers can be direct, indirect or part of a feedback loop, and all drivers listed appear in at least one regime shift included in the RSDB to date. This list provides guidance to maintain consistency in the naming of variables in CLDs for future contributions to the RSDB.

1. Agriculture

2. Aquaculture

3. Aquifers depletion

4. Climate change

5. Coastal erosion

6. Deforestation

7. Disease

8. Droughts

9. ENSO like events

10. Erosion

11. Estuarine fresh water input

12. Estuarine salinity

13. Fertilizers use

14. Fire frequency

15. Fishing

16. Floods

17. Flushing

18. Green house gases

19. Harvesting (animals)

20. Hunting

21 . Ice melt water

22. Impoundments

23. Invasive species

24. Irrigation

25. Landscape fragmentation

26. Logging

27. Low tides

28. Nutrient inputs

29. Ocean acidification
30. Pollutants

31. Precipitation

32. Production intensification

33. Rainfall variability

34. Ranching (livestock)

35. River channelization

36 . Roads and railways

37. Salt water intrusion

38. Sea level rise

39. Sea surface temperature

40. Sea water density

41. Sediments

42. Sewage

43. Soil moisture

44. Storms

45. Temperature

46. Thermal anomalies in summer

47. Turbidity

48. Upwellings

49. Urban storm water runoff

50. Urbanization

51. Water depth

52. Water infrastructure

53. Water level fluctuation

54. Water stratification

55. Water vapor

56. Wetland Drainage

57. Wind stress 
Appendix 2. Regime Shifts Database Template for capturing generic examples of regime shifts. A slightly modified version for capturing detailed case studies is also available at www.regimeshifts.org.

\section{REGIME SHIFTS DATABASE}

\section{GENERIC REGIME SHIFTS TEMPLATE}

GREEN = Free text, paragraph style

BLUE $=$ Free text, brief keywords or phrases

RED $=$ Choose from predefined keyword options

\section{Regime shift name}

Short, succinct name for the type of regime shift. Try to include a brief reference to both regimes (e.g. clear to turbid water). The regime shift types should be generalized descriptions of the dynamics of a particular kind of RS as observed over multiple case studies, rather than a description of the dynamics that occurred in a particular case (e.g. Lake Eutrophication in Lake Mendota). However, for large-scale regional or global RS the case may be unique (e.g. collapse of the thermohaline circulation) and can then be described in unique terms.

\section{Main Contributors}

Names of those who primarily contributed to the text.

\section{Other Contributors}

Names of others who contributed to and reviewed the text.

\section{Summary/Abstract of regime shift (max 150 words)}

Brief, clear, easy-to-understand summary of the regime shift: the alternate regimes, the key drivers (social and ecological), and key impacts. This section is intended to be understandable by lay persons and the general public. Limit the summary to 1 paragraph and do not include references. This section should be written last, once you have finalized all the other sections.

\section{Alternate regimes ( $\max 300$ words)}

This section describes the different regimes that may exist in the system. Use the following structure to write this section:

Para 1: Brief introduction and background to the topic/system. Clearly define the system and its boundaries (eg, lake and its watershed, including the people living in the landscape). Where does the system (eg coral reefs) occur?

\section{Name for Regime 1}

Para 1: Briefly describe what the regime looks like - what do you see in the field? (e.g., clear water, rooted plants on lake floor, limited agriculture in the catchment)

\section{Name for Regime 2}

Para 1: Briefly describe what the regime looks like - what do you see in the field? (e.g., turbid water, dense algal blooms, extensive agriculture in the catchment) 
6. Drivers and causes of the regime shift (max 300 words per shift)

This section contains a description of the key drivers that cause the system to shift from Regime 1 to Regime 2. Include key references. We suggest the following structure:

\section{Shift from Regime 1 to Regime 2}

Para 1: Describe the main causes of the regime shift.

Para 2: Describe other important causes of the regime shift.

Where applicable, do the same for the shift from regime 2 to regime 1.

7. How the regime shift works (max 400 words per shift)

This section describes in lay terms how the drivers and feedbacks interact to cause the system to shift from Regime 1 to Regime 2 and vice versa. Include key references. We suggest the following structure for this section:

\section{Shift from Regime 1 to Regime 2}

Para 1: Describe how Regime 1 works: under which conditions does it occur, and what feedbacks maintain the regime?

Para 2: Describe how the key drivers cause the system to cross key thresholds and move into Regime 2.

Para 3: Describe how Regime 2 works, and the key feedbacks that maintain the regime.

Where applicable, do the same for the shift from regime 2 to regime 1.

8. Impacts on ecosystem services and human well-being (max 200 words per shift) This section describes the impacts of the regime shift on ecosystems, ecosystem services (provisioning, regulating, cultural) and human well-being.

\section{Shift from Regime 1 to Regime 2}

Para 1: Which ecosystem services are lost and gained with this regime shift?

Para 2: What impacts does this have on human well-being? Who benefits and loses?

Where applicable, do the same for the shift from regime 2 to regime 1.

\section{Options for managing the regime shift (max 300 words)}

Describe the options for preventing undesirable regime shifts or restoring/encouraging desirable regime shifts. Use the following structure to write this section:

Para 1: Options for preventing regime shift (ie, enhancing resilience). What management actions or interventions can be taken to maintain desirable regimes and avoid undesirable regime shifts? 
Para 2: Options for restoration of desirable regimes (ie, reducing resilience to encourage restoration or transformation). What management actions or interventions can be taken to transform to or restore desirable regimes?

\section{Key References}

References cited in the paragraph descriptions and other key references

The following fields serve as a summary of the details above, and their main purpose is to enable database searches. Highlight the options that apply:

\section{Key direct drivers of the RS}

11.1. Vegetation conversion and habitat fragmentation

11.2. Harvest and resource consumption

11.3. External inputs (eg fertilizers, pest control, irrigation)

11.4. Adoption of new technology (eg new fishing nets)

11.5. Infrastructure development (eg roads, pipelines)

11.6. Species introduction or removal

11.7. Disease

11.8. Soil erosion \& land degradation

11.9. Environmental shocks (eg fire, floods, droughts)

11.10. Global climate change

\section{Land use under which the RS occurs}

12.1. Urban

12.2. Small-scale subsistence crop cultivation

12.3. Large-scale commercial crop cultivation

12.4. Intensive livestock production (eg feedlots, dairies)

12.5. Extensive livestock production (natural rangelands)

12.6. Timber production

12.7. Fisheries

12.8. Mining

12.9. Conservation

12.10. Tourism

12.11. Land use impacts are primarily off-site (e.g. dead zones in the ocean caused by fertilizer use in the interior; also indicate the relevant land uses above)

\section{Ecosystem type in which the RS occurs}

13.1. Marine \& coastal

13.2. Freshwater lakes \& rivers

13.3. Temperate \& Boreal Forests

13.4. Tropical Forests

13.5. Moist savannas \& woodlands

13.6. Drylands \& deserts (below $\sim 500 \mathrm{~mm}$ rainfall/year)

13.7. Mediterranean shrub (e.g. fynbos)

13.8. Grasslands

13.9. Wetlands

13.10. Tundra

13.11. Polar

13.12. Agro-ecosystems

13.13. Planetary 


\section{Impacts on Key Ecosystem Processes}

14.1. Soil formation

14.2. Primary production

14.3. Nutrient cycling

14.4. Water cycling

\section{Impacts on Biodiversity}

15.1. Biodiversity

16. Impacts on ecosystem services

16.1. Provisioning services

Freshwater

Food Crops

Livestock

Fisheries

Wild animal and plant products

Timber

Woodfuel

Feed, fuel and fiber crops

Hydropower

16.2. Regulating services

Air quality regulation

Climate regulation

Water purification

Regulation of soil erosion

Pest \& disease regulation

Pollination

Natural hazard regulation

16.3. Cultural services

Recreation

Aesthetic values

Knowledge and educational values

Spiritual and religious

\section{Impacts on Human Well-being}

17.1. Food and nutrition

17.2. Health (eg toxins, disease)

17.3. Livelihoods and economic activity

17.4. Security of housing \& infrastructure

17.5. Aesthetic and recreational values

17.6. Cultural identity

17.7. Social conflict

17.8. No direct impact

\section{Typical spatial scale at which RS occurs}

18.1. Local/landscape (e.g. lake, catchment, community)

18.2. National (country)

18.3. Sub-continental (e.g. southern Africa, Amazon basin)

(actual RS mechanism occurs at the regional scale OR cumulative impact/extent of local-scale RS is regional in scale)

18.4. Global 
19. Typical time scale over which RS occurs
19.1. Weeks
19.2. Months
19.3. Years
19.4. Decades
19.5. Centuries
19.6. Unknown

\section{Reversibility of RS}

20.1. Irreversible (on 100 year time scale)

20.2. Hysteretic (difficult to reverse)

20.3. Readily reversible

20.4. Unknown

\section{Evidence}
21.1. Models
21.2. Paleo-observation
21.3. Contemporary observations
21.4. Experiments
21.5. Other

\section{Confidence: Existence of RS}

22.1. Speculative - Regime shift has been proposed, but little evidence as yet

22.2. Contested - Reasonable evidence both for and against the existence of RS

22.3. Well established - Wide agreement in the literature that the RS exists

\section{Confidence: Mechanism underlying RS}

23.1. Speculative - Mechanism has been proposed, but little evidence as yet

23.2. Contested - Multiple proposed mechanisms, reasonable evidence both for and against different mechanisms

23.3. Well established - Wide agreement on the underlying mechanism

\section{Links to other regime shifts}

List other regime shifts that may be triggered by or that may trigger the current regime shift (eg lake eutrophication is often linked to hypoxia and fisheries collapse).

\section{Diagrams/Photos illustrating the regime shift}

Diagrams or photographs that illustrate the regime shift or concisely summarize the key drivers and dynamics of the regime shift. Each figure should be accompanied by a caption and information about the source (credit or html link). Only use open-source material. 


\section{REGIME SHIFT ANALYSIS (OPTIONAL)}

\section{Causal loop diagram illustrating the regime shift}

The figure should illustrate the dynamics of the integrated SES, not only the ecological system. You will usually develop the CLD iteratively as you work through the template.

\section{Feedback mechanisms}

This section contains a description of the known or proposed feedback mechanisms that maintain each regime. Note that the same mechanism can act to maintain both regimes (eg albedo can both maintain ice and open water) - in this case describe how the feedback works to maintain each regime. Include key references. Use the following structure to write this section:

\section{Name of Regime 1}

- Name of feedback mechanism 1 (scale, uncertainty): Describe how the feedback works to maintain the regime. Note the scale at which the feedback operates (local, regional or global), and whether it is well-established, contested or speculative.

- Name of feedback mechanism 2 (scale, uncertainty): Describe how the feedback works to maintain the regime. Note the scale at which the feedback operates (local, regional or global), and whether it is well-established, contested or speculative.

- Etc.

\section{Name of Regime 2}

- Name of feedback mechanism 1 (scale, uncertainty): Describe how the feedback works to maintain the regime. Note the scale at which the feedback operates (local, regional or global), and whether it is well-established, contested or speculative.

- Name of feedback mechanism 2 (scale, uncertainty): Describe how the feedback works to maintain the regime. Note the scale at which the feedback operates (local, regional or global), and whether it is well-established, contested or speculative.

- Etc.

\section{Drivers of the regime shift}

This section contains a description of the key drivers that cause the system to shift from Regime 1 to Regime 2 and vice versa. Explicitly describe how the drivers affect the system state or the feedback mechanisms identified above in order to cause the shift. The description should not focus purely on the ecological dynamics, but include anthropogenic links and drivers - i.e. describe the regime shift from an SES perspective. Include key references. Use the following structure to write this section (if there are no factors in a particular category, then simply delete that category):

\section{Shift from Regime 1 to Regime 2}

Important shocks (eg droughts, floods) that contribute to the regime shift include:

- Shock 1 (scale, uncertainty): Describe how the shock affects the system state and/or feedbacks to cause the shift. Where possible note the scale at which the 
shock operates (local, regional or global), and whether its effect is wellestablished, contested or speculative.

- Etc.

The main external direct drivers that contribute to the shift include:

- External direct driver 1 (scale, uncertainty): Describe how the driver affects the system state and/or feedbacks to cause the shift. Where possible note the scale at which the driver operates (local, regional or global), and whether its effect is well-established, contested or speculative.

- Etc.

The main external indirect drivers that contribute to the shift include:

- External in direct driver 1 (scale, uncertainty): Describe how the driver affects the system state and/or feedbacks to cause the shift. Where possible note the scale at which the driver operates (local, regional or global), and whether its effect is well-established, contested or speculative.

- Etc.

Slow internal system changes that contribute to the regime shift include:

- Slow variable 1 (scale, uncertainty): Describe how the slow variable affects the system state and/or feedbacks to cause the shift. Where possible note the scale at which the internal system change operates (local, regional or global), and whether its effect is well-established, contested or speculative.

- Etc.

\begin{tabular}{|l|l|l|l|l|}
\hline & Driver (Name) & $\begin{array}{l}\text { Type (Direct, Indirect, } \\
\text { Internal, Shock) }\end{array}$ & $\begin{array}{l}\text { Scale (local, } \\
\text { regional, global) }\end{array}$ & $\begin{array}{l}\text { Uncertainty (speculative, } \\
\text { proposed, well-established) }\end{array}$ \\
\hline 1 & & & & \\
\hline Etc & & & & \\
\hline
\end{tabular}

Where applicable, do the same for the shift from regime 2 to regime 1.

\section{Key Thresholds}

Describe the key thresholds that "tip" the system from one regime to another.

\section{Shift from Regime 1 to Regime 2}

- Threshold 1 - briefly describe

- Threshold 2 - briefly describe

- Etc

\section{Shift from Regime 2 to Regime 1}

- Threshold 1 - briefly describe

- Threshold 2 - briefly describe

- Etc 


\section{Leverage Points}

Describe the key places to intervene in the system - ie key variables and drivers that can be manipulated to enhance resilience of desirable regimes or encourage restoration or transformation. Point out if the leverage points are differ for different actors.

- Leverage point 1 (scale, uncertainty): Describe how the leverage point affects the system state and/or feedbacks to effect change in the system. Where possible note the scale and level of certainty about the leverage point.

- Etc.

31. Ecosystem Service \& Human Wellbeing Impacts

Detailed, systematic description of ecosystem service impacts. List by the following categories and identify how the changes affect different user groups in different ways. Complete the following table:

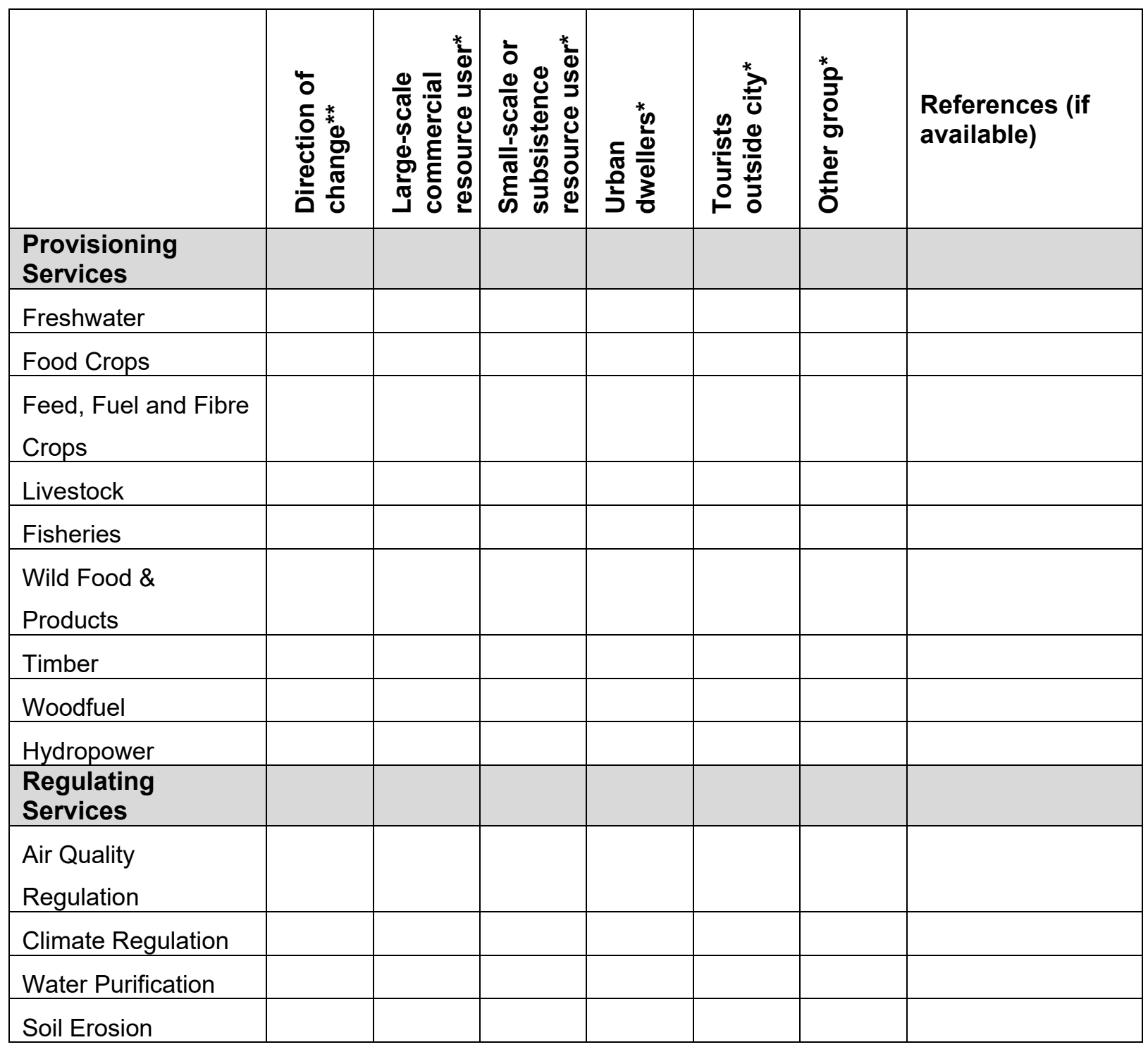




\begin{tabular}{|l|l|l|l|l|l|l|l|}
\hline Regulation & & & & & & & \\
\hline Pest \& Disease & & & & & & & \\
\hline Pogulation & & & & & & & \\
\hline $\begin{array}{l}\text { Protection against } \\
\text { Natural Hazards }\end{array}$ & & & & & & & \\
\hline Cultural Services & & & & & & & \\
\hline Recreation & & & & & & & \\
\hline Aesthetic Values & & & & & & & \\
\hline $\begin{array}{l}\text { Cognitive \& } \\
\text { Educational }\end{array}$ & & & & & & & \\
\hline $\begin{array}{l}\text { Spiritual \& } \\
\text { Inspirational }\end{array}$ & & & & & & & \\
\hline
\end{tabular}

*Use one of the following 5 options for direction of change:

i. $\quad$ Increase $=+$

ii. Decrease $=$ -

iii. Context-dependent (sometimes increases, sometimes decreases) $=+/$ -

iv. $\quad$ No change $=0$

v. Uncertain/unknown = ?

32. Uncertainties and unresolved issues

Note any uncertainties or unresolved issues regarding the regime shift. 
APPENDIX 3. Multidimensional scaling cluster analysis of regime shifts based on their impacts on ecosystem services, for the 28 generic regime shifts currently in the database.

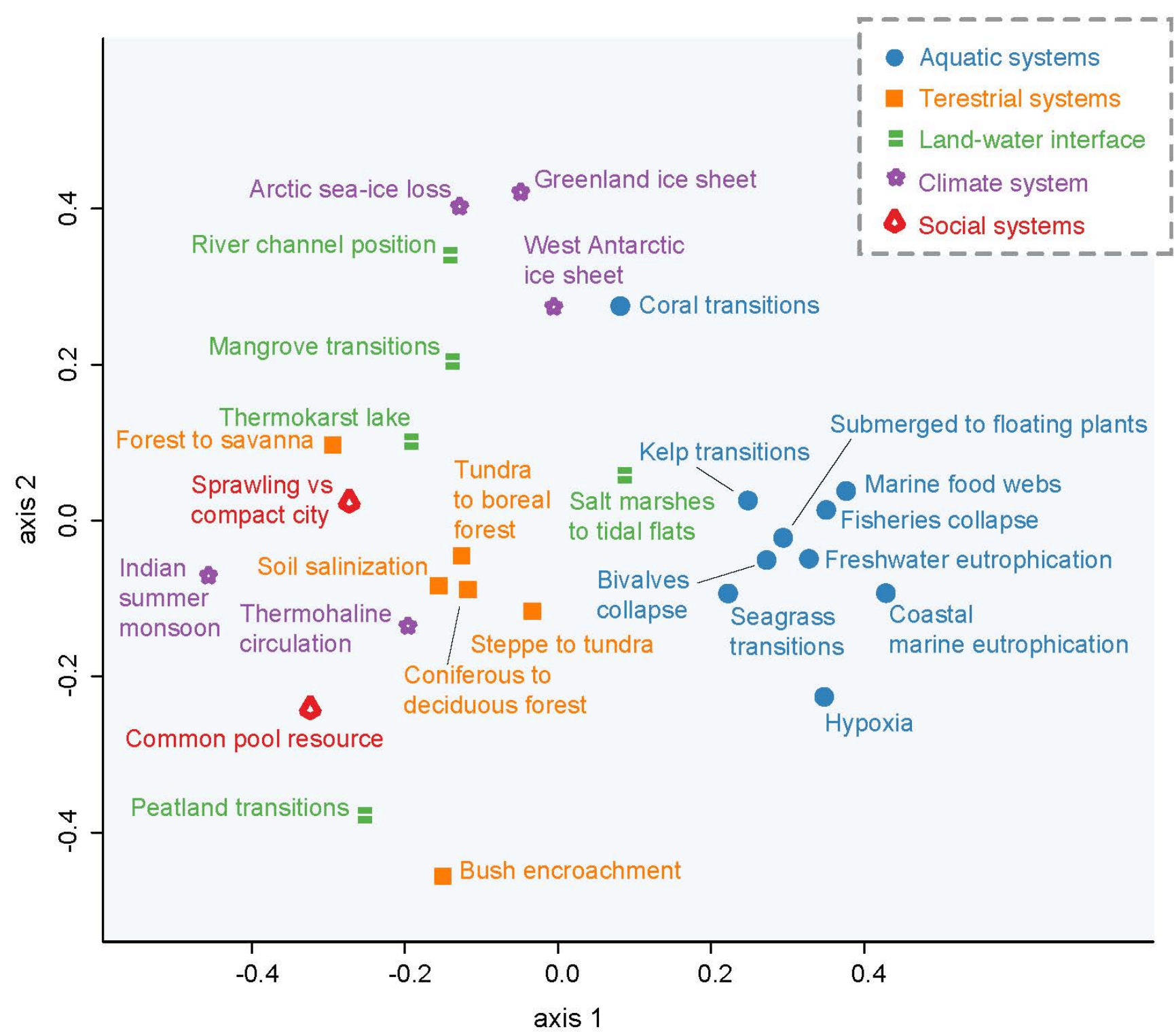

